Printed

August 6, 1990

RFP --4253

DE91 000503

\title{
SUPERPLASTIC DEFORMATION PROPERTIES OF Ti-6Al-4V
}

\author{
M. A. Zacione
}

M. M. McDonald

SURJIECI DESCRIPTORS

Strain-Rate Sensilivity

Superplasticity 'Tïtanium

\section{EG\&G ROCKY FLATS, INC. \\ ROCKY FLATS PLANT}

P.O. BOX 464

GOLDEN, COLORADO 80402-0464

\section{PREPARED UNDER CONTRACT DE-AC04-90DE62349 \\ FOR THE \\ ALBUQUERQUE OPERATIONS OFFICE \\ U.S. DEPARTMENT OF ENERGY}




\section{CONTENTS}

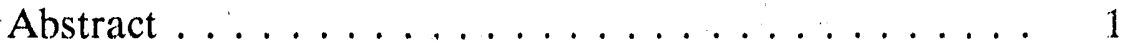

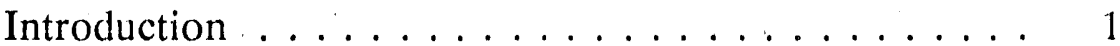

Experiment ${ }^{2}$ Procedure $\ldots \ldots \ldots \ldots \ldots$

Results and Discussion . . . . . . . . . . 5

Material Characterization ........... 5

High-Temperature Deformation Behavior . . . 5

Strain Rate Sensitivity . . . . . . . . . 9 9

Heat Variability Effects

on Superplastic Behavior . . . . . . . 16

Model for Superplastic

Forming of Ti-6Al-4V . . . . . . . . . . . 17

Mechanism and Model for

Superplastic Deformation ............ 17

Effects of Temperature ............. 19

Effect of Grain Size . . . . . . . . . . 20

Effects of Strain and Strain Rate ............... 21

Superplastic Forming of Ti-6Al-4V . . . . . . . 22

Summary $\ldots \ldots \ldots \ldots \ldots \ldots \ldots \ldots \ldots$

References ................... 23 
RFP-4253

\title{
SUPERPLASTIC DEFORMATION PROPERTIES OF Ti-6Al-4V
}

\author{
M. A. Zaccone and M. M. McDonald
}

\begin{abstract}
Superplastic forming of Ti-6Al-4V was investigated with three heats of material to examine the effects of extrinsic and intrinsic variables on strain rate sensitivity and flow stress. Tension tests with strain rate jumps and step strain rate tests were used to determine the effects of strain rate, strain, and temperature on strain rate sensitivity of Ti-6Al-4V. Superplastic forming of Ti-6Al-4V is strongly influenced by deformation temperature. The uniform elongation and the strain rate sensitivity were maximized at $900{ }^{\circ} \mathrm{C}$ in the temperature range tested. In the strain rate range tested, strain rate sensitivity increased slightly as the strain rate decreased.
\end{abstract}

In examining the results, it was apparent that at high strains, grain growth decreased strain rate sensitivity. This decrease was a strong function of temperature, which minimized at $875^{\circ} \mathrm{C}$. The strong dependence of superplastic behavior on temperature can be related to relative amounts of alpha and beta in the microstructure, as shown in the model for superplastic deformation of Ti-6Al-4V.

The data and the model indicate that at optimum temperature for the strain rate range tested, superplastic behavior is dominated by a combination of grain boundary sliding and dislocation creep. The three heats exhibit some microstructural variability, which did not result in significant differences in superplastic behavior.

\section{INTIRODUCTION}

Superplasticity is the ability to achieve large tensile elongations exceeding $500 \%$ in polycrystalline materials under certain conditions of strain rate and temperature. The remarkable formability of superplastic materials is due to their high strain rate sensitivity associated with grain boundary sliding as the principal mechanism of plastic flow. Therefore, superplastic behavior requires deformation of materials with a fine, stable grain size occurring at elevated temperatures and slow strain rates where deformation mechanisms, such as grain boundary sliading, dislocation creep, and diffusional creep, predominate.

The microstructural features important for developing superplastic structures include:

1. Size of the grains.

2. Amount, strength, size, and distribution of a second phase.

3. Nature, mobility, and resistance to tensile separation of grain boundaries.

4. Grain shape. ${ }^{1}$

Ti-6Al-4V typically has a grain size between 5 and 10 microns when conventionally processed. Also, at elevated temperatures, this alloy contains varying volume fractions of alpha (hexagonal, close-packed, titanium-rich phase) and beta (high-temperature, body-centered-cubic phase). The small initial grain size, presence of a high-temperature stable phase with high diffusivities, and relative 
ductility of the alpha phase lend Ti-6Al-4V to superplastic behavior at high temperatures. $^{2}$

Fined-grained Ti-6Al-4V becomes superplastic when tested just below the $\alpha+\beta / \beta$ transformation temperature. Elongations easily exceed $100 \%$ when Ti-6Al-4V is superplastic; and under proper conditions, elongations exceed $400 \%$. Aside from the improved formability, superplastic forming offers reduced cost, improved structural performance, inherent weight reduction, and reduced lead time in production. ${ }^{3}$ Superplasticity also presents reduced forming stresses and no spring-back; hence, it reduces the number of subsequent machining operations and produces a finegrained uniform microstructure compared with conventional forming operations. In general, superplastic forming of materials offers significant advantages; thus; considerable interest in this process has been generated at the Rocky Flats Plant.

Superplastic forming of $\mathrm{Ti}-6 \mathrm{Al}-4 \mathrm{~V}$ requires the application of a constant strain rate at elevated temperatures. The strain rate at which superplastic behavior occurs is much lower than conventional forming operations. However, the increased formability provides aforementioned advantages that far outweigh the increased cycle times. In forming Ti-6Al-4V sheet, the desired strain rate is achieved by varying the pressure over the sheet with time as the material conforms to the die in a process called blow forming. Superplasticity allows relatively large strains during forming, which are somewhat limited because of thinning of the sheet material. Ideally, temperature and pressure should be kept to a minimum to increase tool life. The optimum temperature and pressure are functions of the maximum strain, imposed strain rate, and strain rate sensitivity of the material.
Rockwell's North American Aircraft Operations has performed superplastic forming of Ti-6Al-4V components for the B-1 using the above process. Typical parameters are: 15 to $150 \mathrm{psi}$ pressure at $900-950{ }^{\circ} \mathrm{C}$ for 15 minutes to 4 hours, depending on sheet thickness and part configuration. This process has successfully formed $1.0-$ to $4.6-\mathrm{mm}$ sheet where elongations of 300 to $500 \%$ were reported. Cost and weight trade studies indicate weight savings exceeding $30 \%$ and cost savings exceeding $50 \%$ for the superplastically formed part. ${ }^{4}$

For Rocky Flats to utilize superplastic forming, several milestones must be accomplished. Initially, the parameters by which Ti-6Al-4V becomes superplastic must be understood. This is best accomplished by examining effects of temperature, strain rate, and strain on the strain rate sensitivity parameter, $m$, in tensile tests. ${ }^{5}$ In addition to the extrinsic variables, the effect of intrinsic variables (such as heatto-heat variability of Ti-6Al-4V on strain rate sensitivity) must be investigated to ensure reproducible results on a production basis.

After the material characterization is complete, the pressure profile is determined with proprietary computer programs and information from the tension test. In this stage, critical areas during part forming must be analyzed, taking into account sheet thinning and frictional effects. The various curves are then combined to form a pressure profile versus time such that the strain rate of the process is controlled to prevent ductility loss. Finally, with process parameters established, test parts are formed and their properties are determined to verify the structural integrity. This report addresses the first stage of this process by examining 
the important intrinsic and extrinsic variables applied to the superplastic forming of Ti-6Al-4V.

\section{EXPERIMENTAL PROCEIUUE}

To examine variations between heats on strain rate sensitivity, three sources or heats were selected. These heats were examined for chemical composition and microstructural characteristics, such as grain size, grain aspect ratio, and the phases present. To reduce the number of required tests, an experimental matrix was selected with assistance from Statistical Applications. See Figure 1. Heat 1 was tested under eight different experimental conditions. Heats 2 and 3 were tested under identical conditions, such that the experimental conditions fall within the first set; thus, all three heats may be compared to examine variations.
Tensile tests were used to determine strain rate sensitivity as a function of test temperature, strain, and strain rate. The tension sample, shown in Figure 2, was cut from 0.33-in.-thick plate in the longitudinal direction. The gage length was 1.0 in., cut by an electron discharge method such that surface microstructure was unaffected. Tension tests were performed at a constant strain rate with four temporary strain rate jumps of $40 \%$ at periodic strain values between 0 and $2.0 \mathrm{in} . / \mathrm{in}$. During the tension tests, a constant crosshead speed results in a decreasing strain rate as the gage length increases; thus, the strain rate was maintained constant by programming the crosshead speed to increase with specimen elongation. ${ }^{5}$ The strain rate sensitivity was calculated with the relationship:

$$
\mathrm{m}=\frac{\log \left[\mathrm{P}_{2} / \mathrm{P}_{1}\right]}{\log (\mathrm{X} \dot{\epsilon})}
$$

FIGURE 1. Test Matrix of Superplastic Forming Study

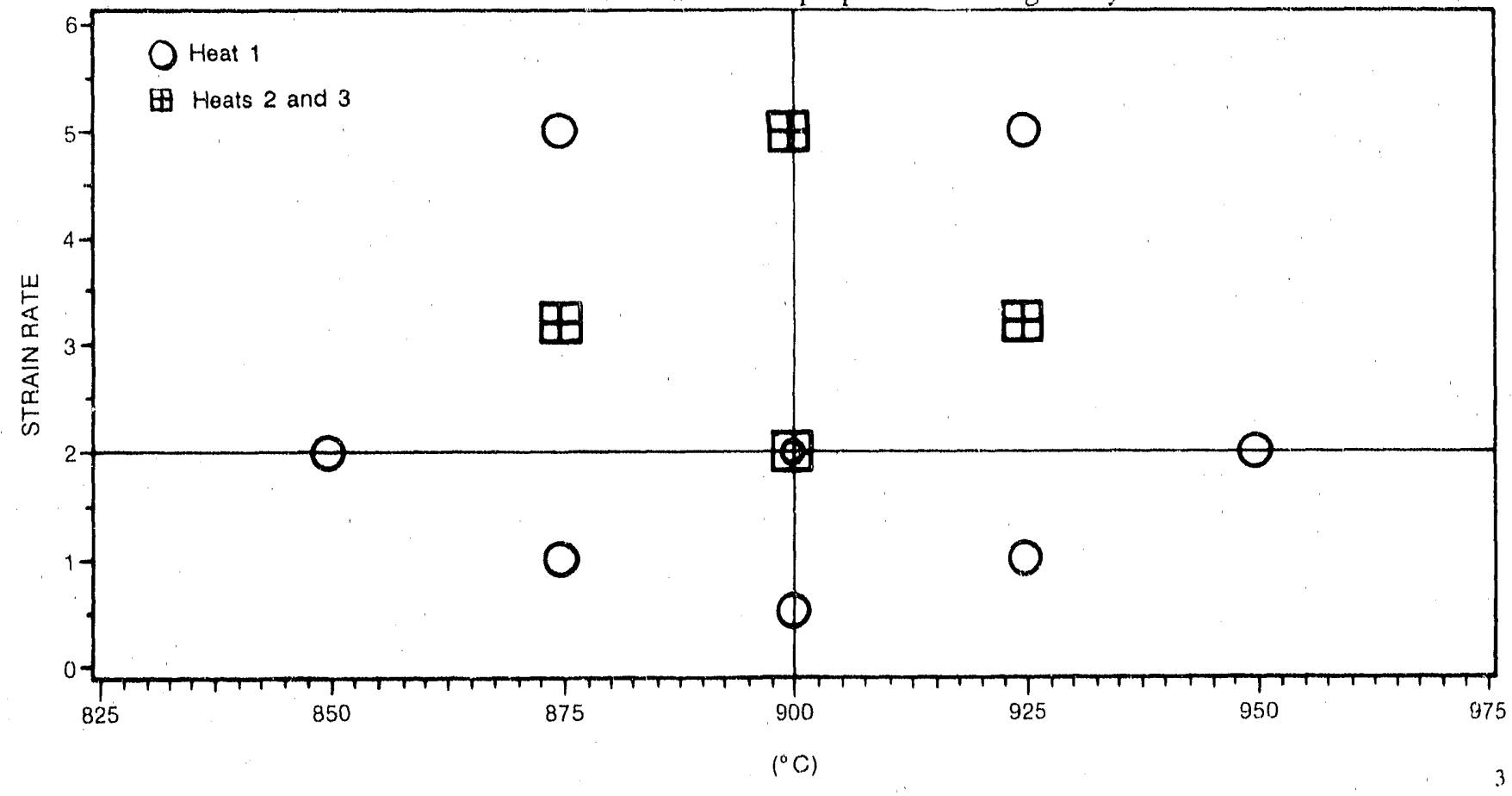




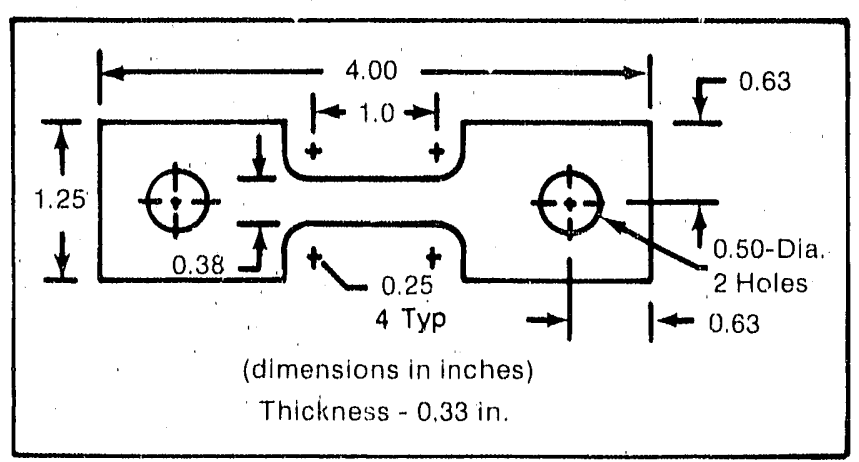

FIGURE 2. Tensile Specimen for Determining Strain Rate Sensitivity in Jump Tests and Step Strain Rate Tests.

where $P_{2}$ is the load at the increased strain rate, $P_{1}$ is the load before the jump, and $X \dot{\epsilon}$ is the strain rate increment. Work by Hamilton and Ghosh indicates that the step strain-rate test is the truest measure of the strain rate sensitivity important to forming studies. ${ }^{6}$ A typical true stress-strain output curve is shown in Figure 3.

After tension testing, samples were selected to examine changes in the grain size as a function of strain and thermal history. The mechanical testing data were analyzed using an SAS statistical package to examine effects of strain, strain rate, and temperature on the strain rate sensitivity parameter, $\mathrm{m}$, as well as to examine any differences between the heats of material. For analysis purposes, four parameters related to strain rate sensitivity were defined:

1. Mean $m$ - The statistical mean of the four strain rate sensitivity values attained at selected true strains during the jump test.

2. Standard deviation - The standard deviation of the four strain rate sensitivity values attained at selected true strains during the jump test.

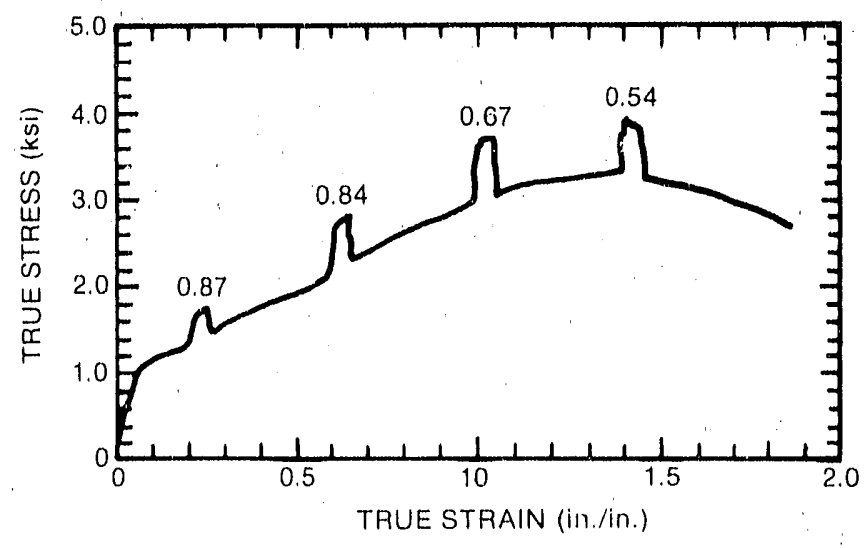

FIGURE 3. Sample Output From Strain Rate Jump Tests Performed on Heat 1 at $925^{\circ} \mathrm{C}$ and a Strain Rate of $5.0 \times 10^{-4}$. The numbers above the increases in flow stress represent calculated strain rate sensitivily from Equation 1.

3. Minimum $m$ - The smallest of the four strain rate sensitivity values attained at selected true strains during the jump test.

4. Slope - The slope of a linear regression best-fit line of the four strain rate sensitivity values by assigning the dependent values $1,2,3$, and 4 to the strain rate sensitivities attained at $40 \%$ increments of true strain during the jump test. The slope is, therefore, the incremental increase of decrease in the strain rate sensitivity per $40 \%$ increment in true strain.

In addition to the jump tests, one specimen was subjected to a strain rate step test in which the strain rate was increased incrementally from $6.3 \times 10^{-5}$ to $5.0 \times 10^{-3} \mathrm{sec}^{-1}$ at $925^{\circ} \mathrm{C}$. At each jump in the strain rate, the flow stress was reported and plotted on a log flow stress versus $\log$ strain rate plot. In this plot, the slope of the tangent of the curve represents the strain rate sensitivity, $m$, as 


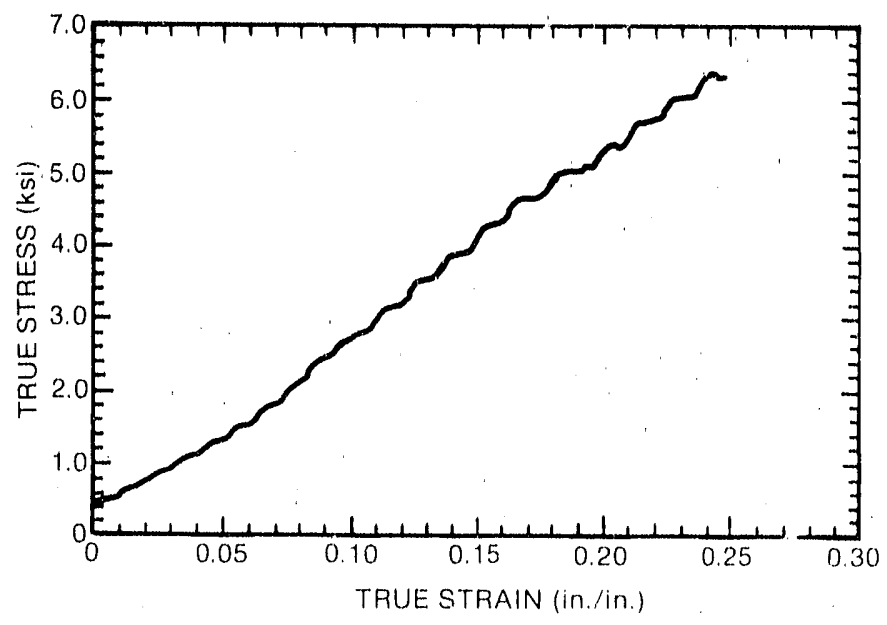

FIGURE 4. Sample Output From the Step Strain Rate Test Performed on Heal 1 at $925^{\circ} \mathrm{C}$. The flow stress after cach increase in strain rate was recorded to determine the strain rate sensitivity as a funclion of strain rale.

a function of strain rate. The strain rate sensitivity was then plotted versus the strain rate. A typical true stress-strain curve for the strain rate step test is shown in Figure 4.

\section{RESULTS AND DISCUSSION}

\section{Material Characterization}

Chemical compositions of the three heats of Ti-6Al-4V are shown in Table 1. All heats were within ASTM requirements for Ti-6Al-4V in the mill-annealed condition shown on the bottom line of the table. Besides aluminum and vanadium, control of the interstitial elements hydrogen, nitrogen, and oxygen is important because of potential effects on the phase equilibria at high temperatures. Generally, interstitial elements are alpha stabilizers; and as reported later, the beta phase has an important role in superplastic behavior of this material.

Microstructures of the three heats consisted of equiaxed primary alpha grains with a small amount of intergranular beta shown in Figure 5. Note that portions of the microstructure contain small areas of incompletely recrystallized transformed beta typical of Ti-6Al-4V supplied in the mill-annealed condition. A summary of the microstructural characteristics is shown in Table 2. All three heats had a uniform grain distribution with grain size in the range of 6.5 to $8.0 \mu \mathrm{m}$. The aspect ratio of the grains varied from 1 to about 6 . Of the three heats, Heat 3 exhibited the largest grain aspect ratio while Heat 2 exhibited an equiaxed microstructure.

\section{High-Temperature Deformation Behavior}

The rate at which strain is applied to a specimen can have an important influence

TABLE 1. Chemical Compositions of Ti-6A1-4V

\begin{tabular}{|c|c|c|c|c|c|c|c|c|}
\hline lleat & & & & & $\%$ & & & \\
\hline No. & $\mathrm{Al}$ & $\mathrm{V}$ & Iic & $C$ & 0 & $\mathrm{~N}$ & II & 1ii \\
\hline 1 & 6.20 & 4.15 & 0.18 & 0.012 & 0.0318 & 0.0005 & 0.0082 & rem \\
\hline 2 & 5.66 & 4.07 & 0.27 & 0.005 & 0,0560 & 0.0024 & $0.0(0444$ & rem \\
\hline 3 & 6.24 & 4.18 & $<0.1$ & 0.011 & 0.0178 & 0.0003 & 0.0069 & rem \\
\hline ASIM & & & & & & & & \\
\hline Requirements & 6.00 & 4.00 & $0.30^{*}$ & $0.10^{*}$ & $0,20)^{\circ}$ & $0.05^{*}$ & $0.0125^{*}$ & $\mathrm{rem}$ \\
\hline
\end{tabular}




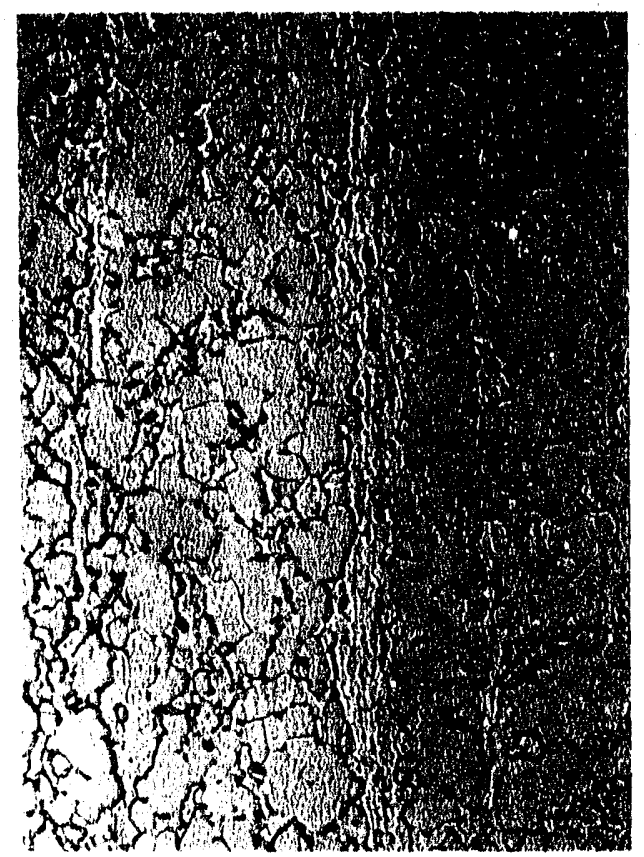

Heat \#1

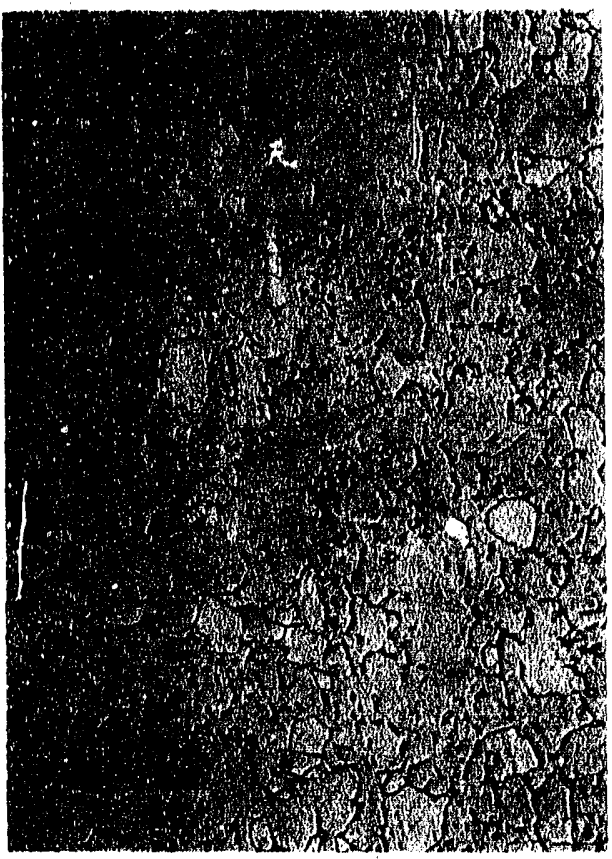

Heat \#2

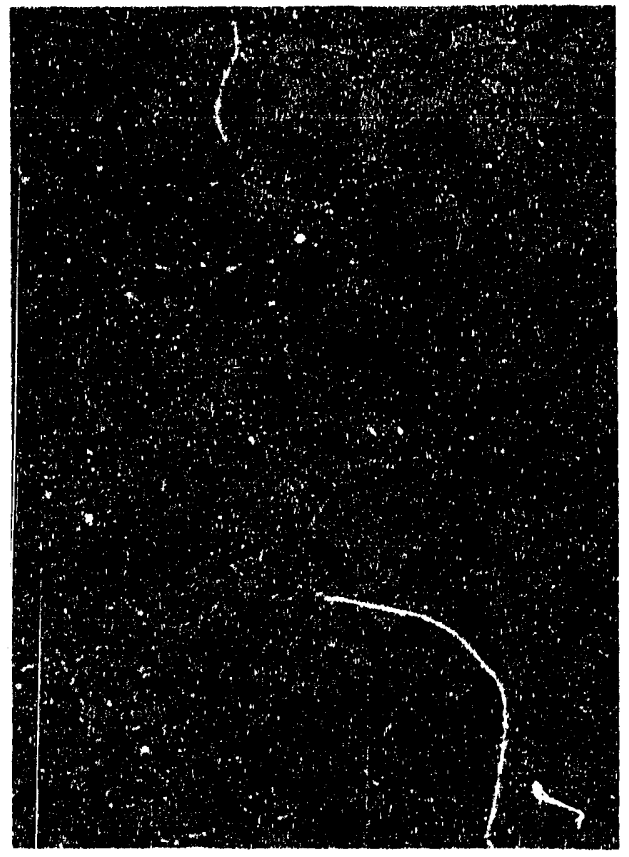

Heat \#3

FIGURE 5. Representative Microstructures From the Three Heats of Material, Consistino of Equiaxed $\alpha$ and Intergranular $\beta$. 400X 
RFP-4253

TABLE 2. Microstructural Characteristics of Ti-6Al-4V

\begin{tabular}{|c|c|c|c|c|}
\hline $\begin{array}{l}\text { Heat } \\
\text { No. }\end{array}$ & $\begin{array}{l}\text { Grilin } \\
\text { Size } \\
\text { (uili) }\end{array}$ & Uniformity & $\begin{array}{l}\text { Aspect } \\
\text { Rillio }\end{array}$ & Microstructure \\
\hline 1 & 6.7 & Yes & $2: 3$ & $\begin{array}{l}\text { Byuiaxed } \alpha \text { and intergranular } B \\
\text { with small amouml. of } \\
\text { untransformed } B \text {. }\end{array}$ \\
\hline 2 & 8.0 & Y's & $1: 2$ & licpuiaxed $\alpha$ and interglanular B. \\
\hline 3 & 6.5 & Yes & $4: 0$ & $\begin{array}{l}\text { liquiaked } \alpha \text { and intergranular a } \\
\text { wilh small anmounts of } \\
\text { clongated } \alpha \text {. }\end{array}$ \\
\hline
\end{tabular}

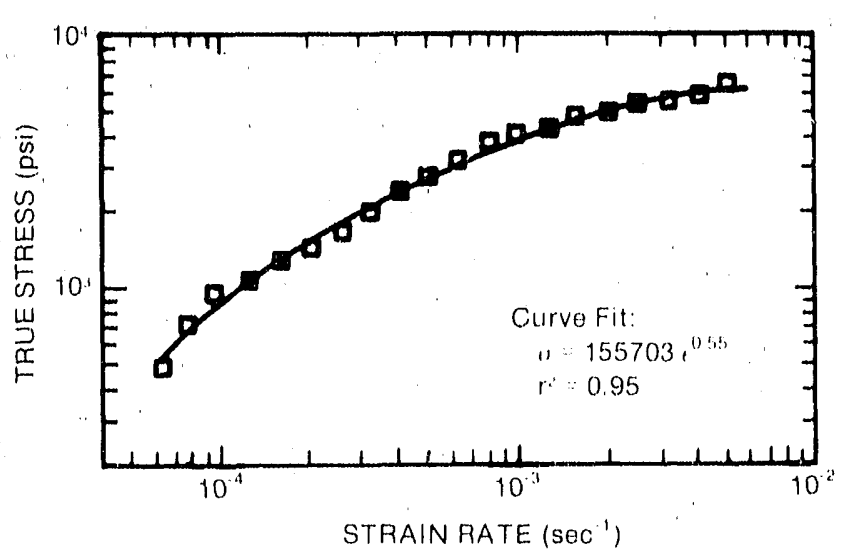

FIciURE 6. True Stress as a Function of Silrain Rate From the Data Acepuired in the Step Surain Rale 'Test at $925^{\circ} \mathrm{C}$.

on flow stress. This fact becomes

especially important when testing materials at high temperatures when thermally activated deformation mechanisms operate. A general relationship between the flow stress $(\sigma)$ and strain rate $(\epsilon)$ at constant temperature and strain is

$$
\sigma=K\left(\dot{\epsilon}_{\mathrm{p}}\right)^{\mathrm{m}}
$$

where $K$ is the stress constant, and $m$ is known as the strain rate sensitivity. ${ }^{7}$ The exponent, $m$, can be obtained from the corresponding flow stress - strain rate values determined in the step strain rate testperformed at $925^{\circ} \mathrm{C}$ (Figure 4). The

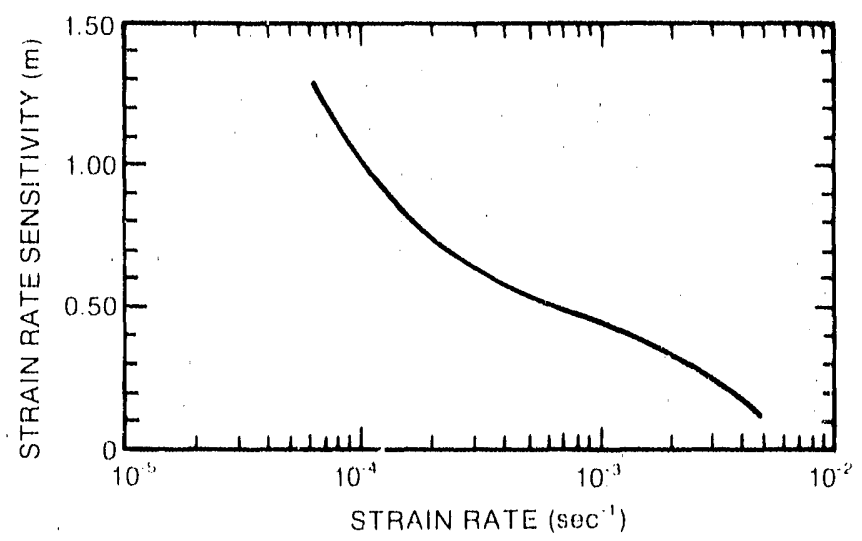

FIGURE 7. Simain Rate Sensitivity as a Function, Sirain Rate for Heal 1 at $925^{\circ} \mathrm{C}$. The curve was acyuired by delermining the slope as a function of strain rate in Figure 6.

slope of the tangent of the log stress versus log sirain rate plot shown in Figure 6 should indicate the value of $m$ as a function of strain rate at $925^{\circ} \mathrm{C}$. By applying an exponential curve fit, the values of $m$ and $K$ were 0.55 and 155.7 $\mathrm{ksi}$, respectively. Differentiating the log stress - log strain rate data in Figure 6 shows that strain rate sensitivity increases with decreasing strain rate as shown in Figure 7.

At strain rates higher than shown in Figure 7 , the strain rate sensitivity should 
maintain a value of approximately 0.2 , corresponding to grain matrix deformation mechanisms. Lowering the strain rates to near $10^{-3}$, corresponding to $\mathrm{m}$ values bctween 0.2 and 0.5 , the superplastic behavior is controlled by dislocation creep mechanisms. ${ }^{8}$ At low strain rates, characterized by a high value of $\mathrm{m}$, the superplastic behavior is associated with grain boundary sliding mechanisms accompanied by grain boundary diffusion. At strain rates lower than shown in Figure 7 , the strain rate sensitivity maximizes before decreasing rapidly in a region defined by diffusional control matrix deformation (Nabbaro-Herring creep). ${ }^{8}$ In this region, dislocation tangles are generated, leading to development of a dislocation substructure and degradation of superplastic properties. For the strain range shown in Figure 7, as the strain rate decreases, superplastic deformation behavior appears to be in a transition stage from dislocation creep mechanisms to grain boundary sliding mechanisms controlled by the material's ability to accommodate dislocations.

The general requirement of a superplastic material, besides a stable fine grain size and a high strain rate sensitivity, is a linear strain versus time creep curve associated with the absence of a developed dislocation substructure after testing. The consequence is an enginecring stress-strain plot, which is similar to an elastic-visco plastic material shown by the dotted line in Figure 8. The steady-state condition implicated by the constant flow stress with strain corresponds to the point at which the total strain rate is constituted by the plastic portion of the strain rate. The rise in load at small strains is due to decrease in the elastic strain rate as the plastic strain rate increases. ${ }^{9}$ The true stressstrain curves acquired at $900{ }^{\circ} \mathrm{C}$ shown in

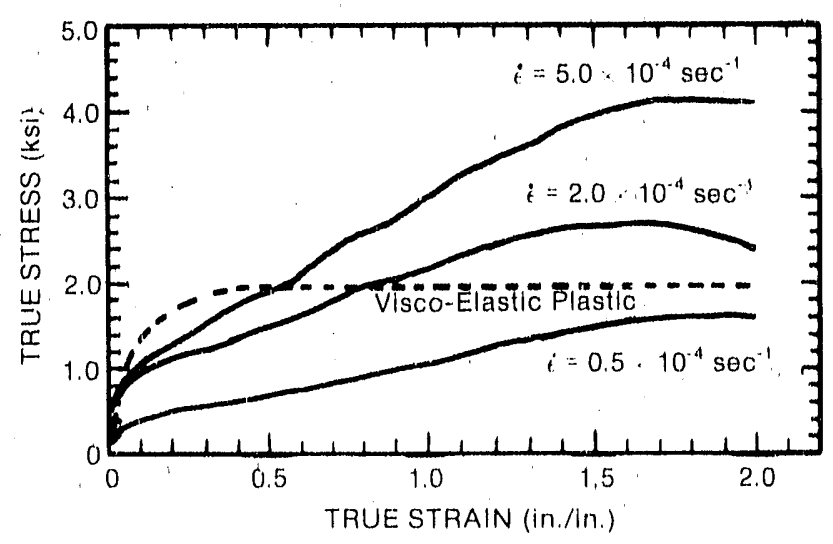

FIGURE 8. True Stress as a Function of True Strain at $900{ }^{\circ} \mathrm{C}$ for Three Different Strain Rates. The doted line represents ideal viscoclastic plastic hehavior in materials.

Figure 8 do not simulate an elastic-visco plastic material. This indicates the possible operation of another hardening mechanism associated with nonuniform grain size, simultaneous grain growth, and/or accumulation of dislocations at the grain boundaries. ${ }^{9,10}$ The flow stress increases with increasing strain rate because of decreased accommodation of dislocation motion, which limits grain boundary sliding and reduces the material's ability to deform superplastically.

Figure 9 shows the true stress-strain curves as a function of temperatures at a constant strain rate of $2.0 \times 10^{-4} \mathrm{sec}^{-1}$. The flow stress increases as the temperature of deformation decreases because of changes in the relative volume fractions of alpha and beta phases. As the test temperature increases from 850 to $950^{\circ} \mathrm{C}$, the volume fraction of beta changes from 0.20 to $0.80 .^{11}$ At high temperatures, the diffusivities of the beta phase is twice that of the alpha phase..$^{11-13}$ Since the flow stress for high-temperature mechanisms decreases as the diffusivity increases, beta is the softest of the phases present. 


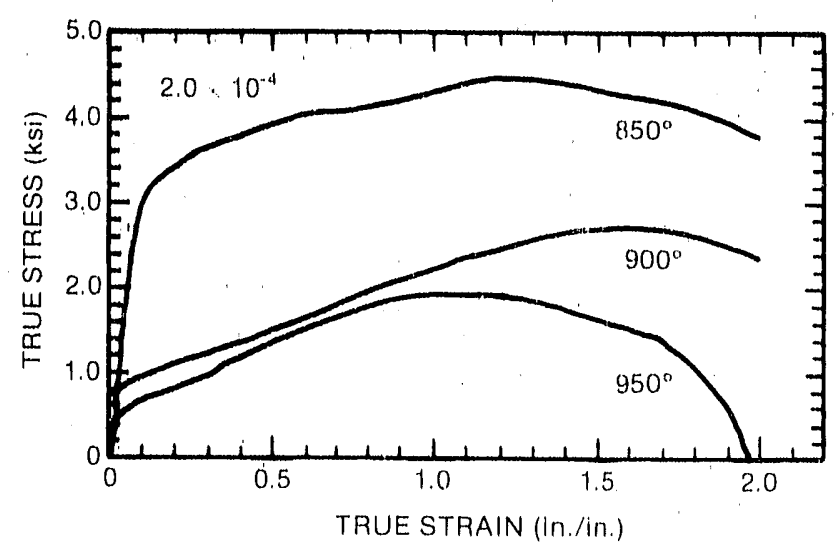

FIGURE 9. True Stress as a Function of 'True Strain at a Strain Rate of $2.0 \times 10^{-4} \mathrm{sec}^{-1}$ for Three Test Temperatures.

Therefore, as the temperature increases, the flow stress decreases caused by an increased volume fraction of beta and increased diffusivity in each phase present.

The ability of a material to deform superplastically can be examined by looking at the true uniform strain or the strain at maximum load in tension. In Figure 9, the $900{ }^{\circ} \mathrm{C}$ test exhibited the largest true uniform strain. As the temperature increases or decreases, the true uniform strain decreases, thereby decreasing formability of the material at these temperatures. A better indication of formability of superplastic materials can be made by examining the strain rate sensitivity discussed in the next section. In summary, high-temperature deformation behavior of $\mathrm{Ti}-6 \mathrm{Al}-4 \mathrm{~V}$ is a strong function of strain rate. Strain rate sensitivities greater than 0.5 (superplastic behavior) occur at strain rates lower than $6 \times 10^{-4}$ $\sec ^{-1}$ at $925^{\circ} \mathrm{C}$. In the strain rate range tested, the mechanism of superplastic behavior appears to be in transition from dislocation creep mechanisms to grain boundary sliding mechanisms controlled by ability of the material to accommodate dislocations. Unlike superplastic behavior, the true stress-strain curves at the tested temperatures do not exhibit elastic-visco plastic behavior, therefore suggesting the operations of additional hardening mechanisms during deformation. The relative volume fraction of alpha and beta affect the flow strength, diffusivities, and grain growth characteristics; thus, temperature, strain rate, and strain will influence the strain rate sensitivity and, ultimately, formability of the material.

\section{Strain Rate Sensitivity}

The mean and minimum strain rate sensitivity data from the jump test were modeled with respect to temperature and strain rate. The temperature and temperature-squared variables were more significant than the strain rate, but all three were significant enough to be included in the model. Analyzing these variables with respect to the strain rate sensitivity yielded the equation:

$$
\begin{aligned}
\text { mean } \mathrm{m}= & -71.85+0.16 \mathrm{~T} \\
& -0.0000893(\mathrm{~T})^{2} \\
& -294.0(\dot{\epsilon})
\end{aligned}
$$

where $\mathrm{T}$ is the temperature $\left({ }^{\circ} \mathrm{C}\right)$ and $\dot{\epsilon}$ is the strain rate $\left(\mathrm{sec}^{-1}\right)$. Likewise, the minimum strain rate sensitivity yielded the equation:

$$
\begin{aligned}
\min \mathrm{m}= & -78.42+0.18 \mathrm{~T} \\
& -0.0001(\mathrm{~T})^{2} \\
& -494.1(\dot{\epsilon}) .
\end{aligned}
$$




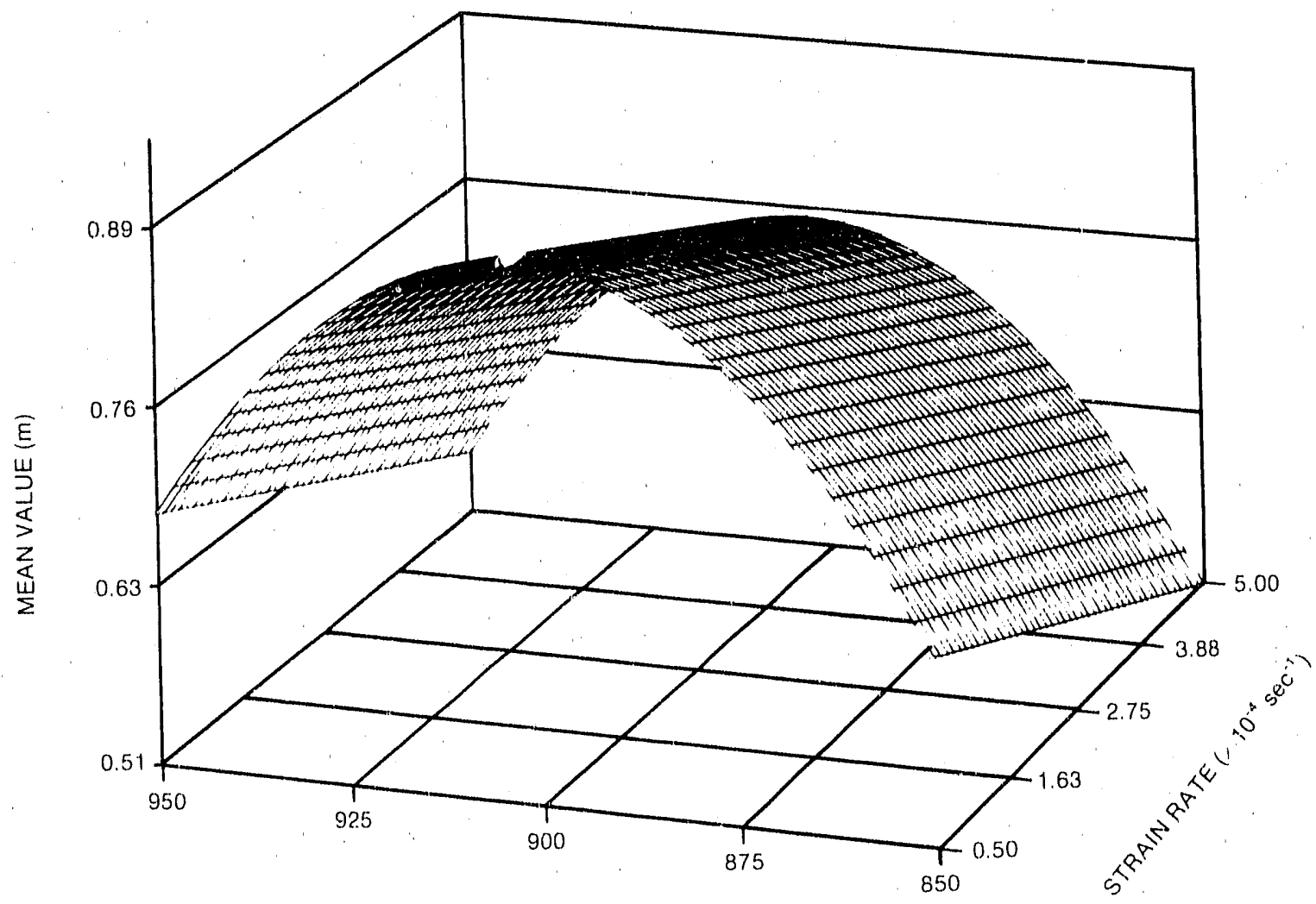

$\left({ }^{\circ} \mathrm{C}\right)$

FIGURE 10. Model (Equation 3) Showing the Effects of Strain Rate and Temperature on the Mean Strain Rate Sensitivity. The Mcan, m, value was defined as the statistical mean of four strain rate sensitivity jump tests taken at different strains during testing.

The coefficient of determination, which indicates the quality of the fit for the mean and minimum strain rate sensitivity were 0.77 and 0.67 . (Values closer to 1.0 indicate a better fit.) Equations 3 and 4 are graphically mapped versus strain rate and temperature in Figures 10 and 11, respectively. Both functions indicate a strong dependence of the strain rate sensitivity on temperature because of thermally activated mechanisnis involved with superplastic behavior.

Strain rate sensitivity varied in a similar manner with respect to temperature and strain rate for both the mean and minimum value across the entire strain range. The strain rate sensitivity increased as the temperature increased in the range from 850 to $900{ }^{\circ} \mathrm{C}$ caused by increased volume fraction of the beta phase and enhanced diffusivities of both phases. As the temperature increased above $900{ }^{\circ} \mathrm{C}$, the decrease in the strain rate sensitivity was due to a large fraction of beta phase and a smaller fraction of alpha phase. There is little grain growth of alpha at high temperatures because of the large beta phase volume, but rapid grain growth occurs because the small amount of alpha phase is insufficient to restrict the betaphase boundaries from migrating. 
RFP-4253

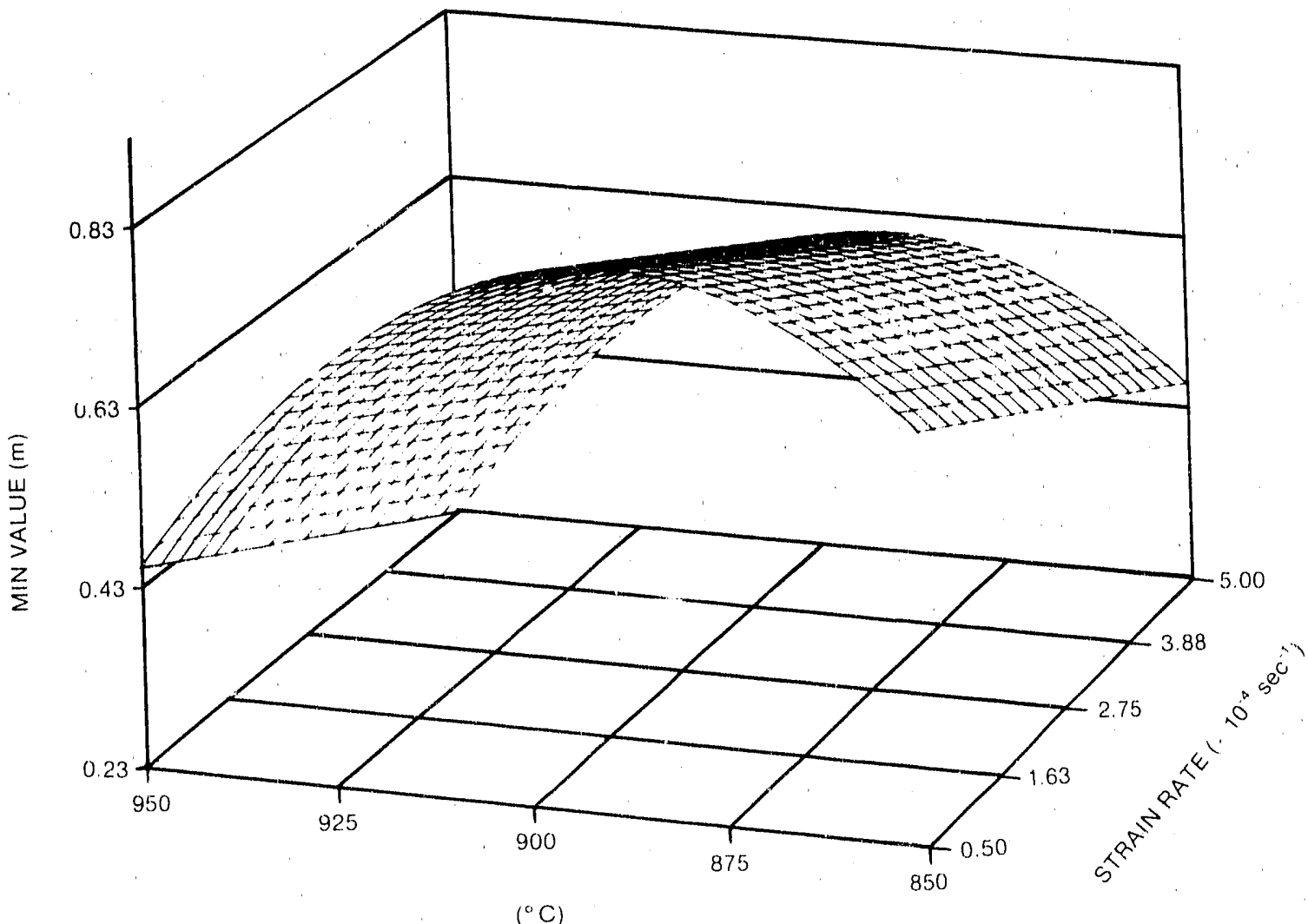

FIGURE 11. Model (Equation 4), Showing the Effects of Strain Rate and Temperature on Minimum Strain Rate Sensitivity. The minimum $m$ value was defined as the smallest of four strain rate sensitivity jump tests taken at different strains during testing.

Therefore, at the higher temperatures, increased grain growth decreases strain rate sensitivity. At $900^{\circ} \mathrm{C}$, a combination of intermediate growth kinetics and approximately equal fraction: of the two phases results in maximum $s$ rain rate sensitivity. At the lower temperatures, a large volume fraction of alpha and a low volume fraction of beta exist; but little grain growth occurs at the low temperatures, and any decrease in the strain rate sensitivity caused by grain growth is easily overcome by increased diffusivities of the phases as temperature is increased.

Both the mean and minimum strain rate sensitivity increased with decreasing strain rate at all temperatures similar to the results of the step strain rate test shown in Figure 7. The rate of decrease in the strain rate sensitivity as a function of strain rate was greatest at $900{ }^{\circ} \mathrm{C}$ (Figure 12). The rate of decrease (or slope) in strain rate sensitivity decreases as the temperature is raised or lowered from 900 ${ }^{\circ} \mathrm{C}$. At higher temperatures, grain growth may act to reduce strain rate sensitivity as the strain rate decreases because of longer times at temperatures, thus reducing the slope in Figure 12. At the lower temperatures, where differences in the strain rate sensitivities were due to varying volume fractions of alpha and beta, the reduced slope of the strain rate sensitivity 
RFP-4253

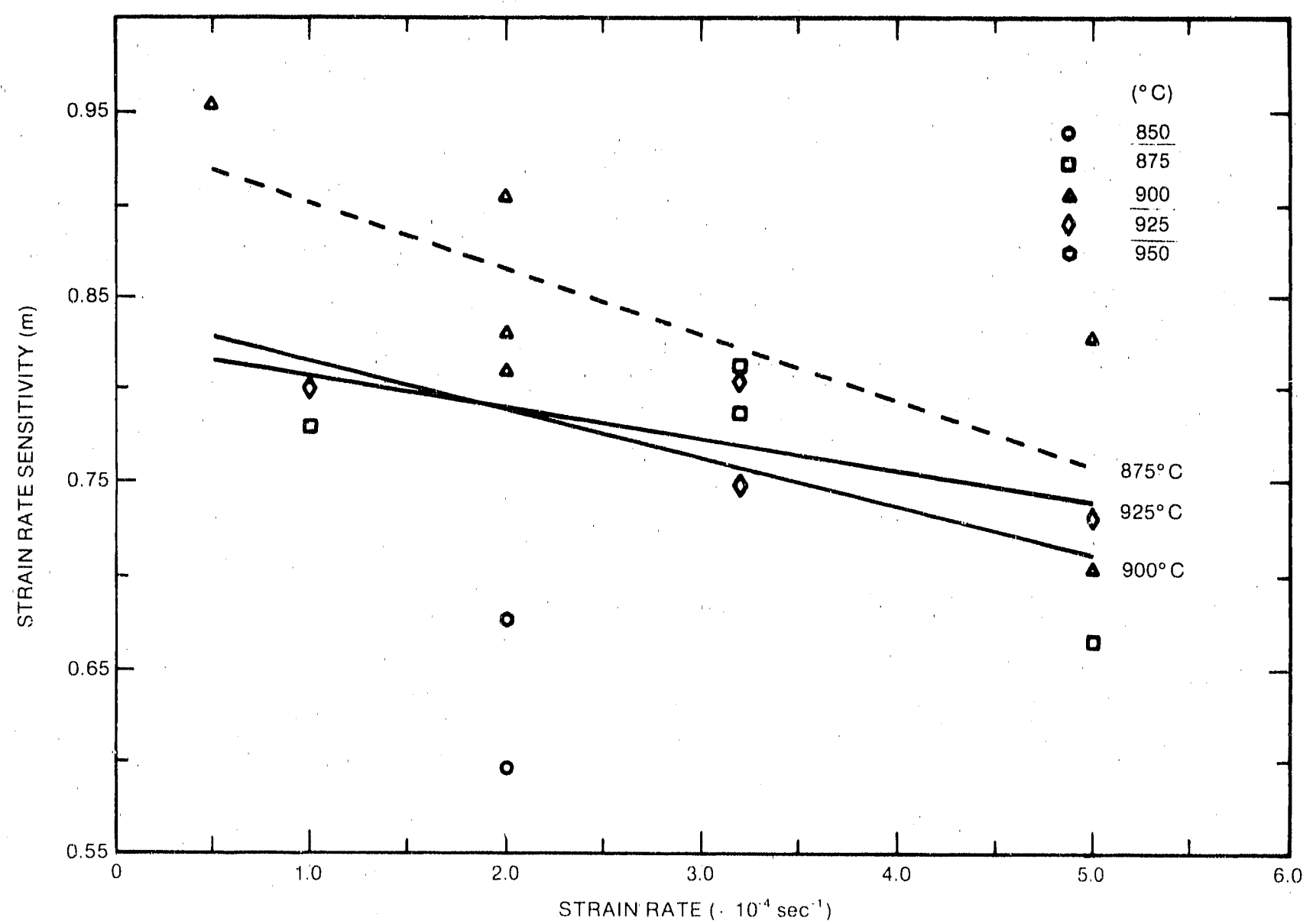

FIGURE 12. Mean Strain Rate Sensitivity, $m$, as a Function of Strain Rate for all Jump Tests Performed. The lines represent the best-lit linear regression for the temperatures given.

with increasing strain rate cannot be explained easily. However, as reported later, the effects of strain rate on strain rate sensitivity are clouded when the strain present at each jump point is included it. the model.

During the jump test, the strain rate sensitivity was measured at several different true strains. Figure 3 shows that strain rate sensitivity decreased with increasing strain at $925^{\circ} \mathrm{C}$. Figure 13 summarizes strain rate sensitivity versus the true strain for all the data. The strain rate sensitivity varies very little with strain at the low temperatures. The strain rate sensitivity increases with temperature at a strain of 0.2 because of an increasing volume fraction of beta phase. However, at temperatures above $900{ }^{\circ} \mathrm{C}$, strain rate sensitivity decreases at strains of 0.60 or greater because of grain growth. The magnitude of the drop increases as strain increases because increased time is necessary to achieve the strain at a constant strain rate and strain-induced grain growth. It has already been established that strain rate sensitivity decreases with increasing strain rate at all the temperatures tested. However, when 


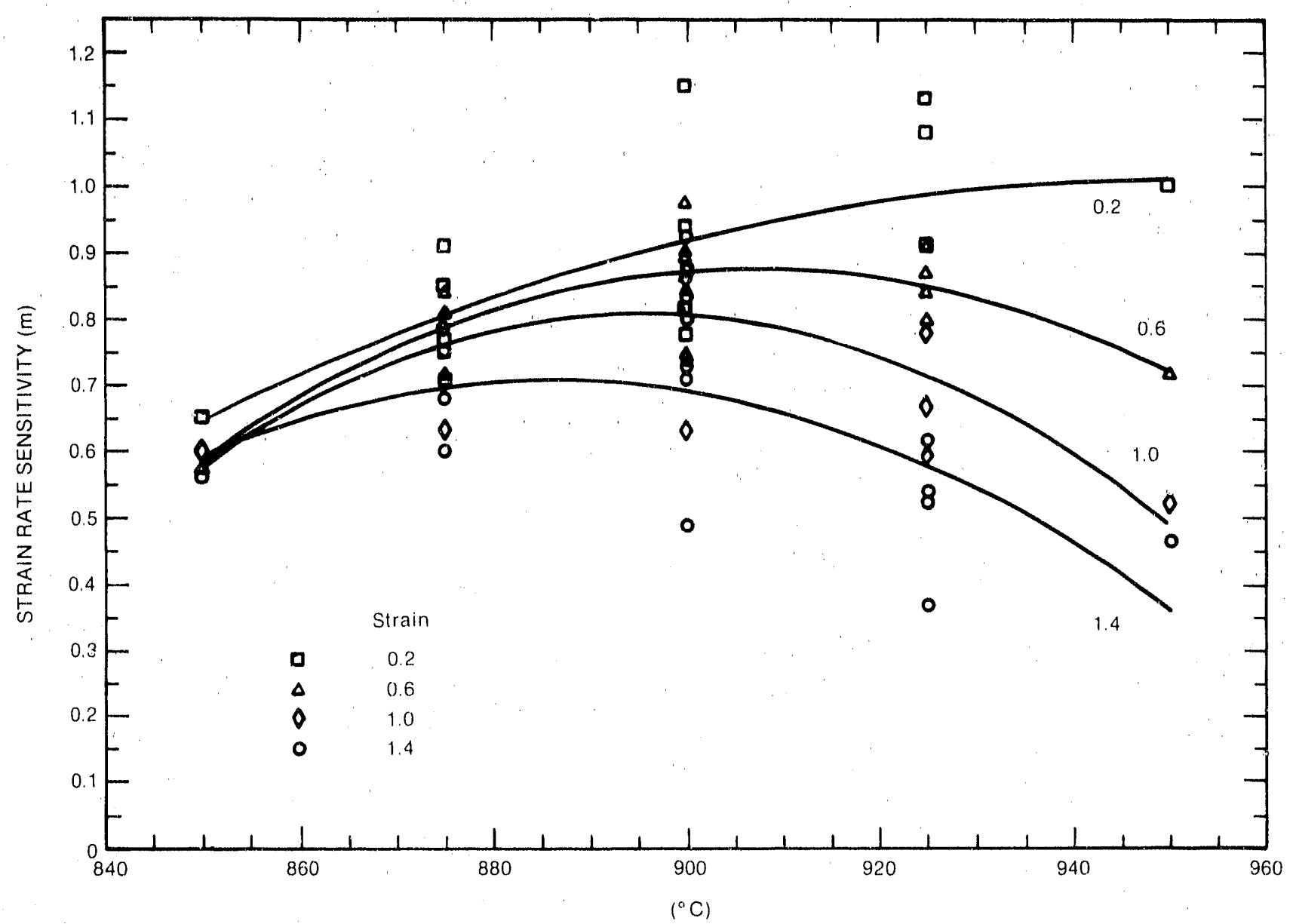

FIGURE 13. Strain Rate Sensitivity at Four Different Strains as a Function of Temperature for all the heats and Strain Rates. The data were obtained from the strain rate jump test summarized in Table 3.

the strain at the jump was included in the model, the data show no correlation with the rate of decrease in the strain rate sensitivity as temperature changes. To further examine the effects of strain, two parameters--the slope and standard deviation (defined earlier)--were processed statistically.

Like the mean and minimum strain rate sensitivity, the slope was also a strong function of temperature and strain rate; the temperature squared, temperature, and strain rate were the significant variables. On the other hand, the standard deviation was a strong function of temperature and temperature squared only, having no significant relationship with strain rate. The coefficients of determination for the slope and standard deviation functions were 0.91 and 0.48 , respectively. The standard deviation was excluded from the model because of its low coefficient of determination.

The standard deviation represents the variability of strain rate sensitivity relative to the mean and not the strain increment. The mean strain rate sensitivity occurs at different strains skewed near the second of 
four strain increments. Therefore, the standard deviation measures the variability of strain rate sensitivity, indirectly resuliting in a large coefficient of error. On the other hand, the slope is a measurement of change in strain rate sensitivity as a function of strain over three strain increments.

Table 3 shows that the relative changes in strain rate sensitivities vary as the strain increases. This change was not accounted for in the slope parameter, because the individual strain rate sensitivities as a function of strain were fitted with a linear regression. However, Figure 13 shows that at constant temperatures the relative change in strain rate sensitivity as a function of strain was fairly constant when the data are fit with temperature as a quadratic function. (Remember, temperature and temperature squared were most significant variables.) As a result, the high coefficient of determination and the constant change of the strain rate sensitivity with strain demonstrate the slope variable is a good indication in examining changes in strain rate sensitivity with strain as a function of temperature and strain rate.

Analysis of the slope function yields the following equation for the slope:

$$
\begin{aligned}
\text { slope }=- & 64.99+0.148 \mathrm{~T} \\
& 0.000845(\mathrm{~T})^{2} \\
- & 181.6(\dot{\epsilon})
\end{aligned}
$$

with $\mathrm{T}$ as the temperature $\left({ }^{\circ} \mathrm{C}\right)$ and $\dot{\epsilon}$ as the strain rate $\left(\mathrm{sec}^{-1}\right)$. Figure 14 shows the graphical representation of Equation 5 for the temperature and strain rate range of interest. The slope function is a strong function of temperature maximizing near zero (representing no effect of strain on strain rate sensitivity) between 870 and $880{ }^{\circ} \mathrm{C}$. At higher temperatures, the slope

\begin{tabular}{|c|c|c|c|c|c|c|c|c|c|}
\hline \multirow[b]{2}{*}{$\begin{array}{l}\text { Ileall } \\
\text { No. }\end{array}$} & \multirow[b]{2}{*}{$\begin{array}{l}\text { l'cmp. } \\
\text { ("C) }\end{array}$} & \multirow{2}{*}{$\begin{array}{l}\text { Strain } \\
\text { Ralle } \\
\left(10^{-4}\right. \\
\left.\sec ^{-1}\right) \\
\end{array}$} & \multicolumn{7}{|c|}{ Strain Rate Sonsitivity (m) } \\
\hline & & & $0.2 *$ & $0,6^{*}$ & $1 .()^{*}$ & $1.4^{*}$ & Meil! & Slone & $\begin{array}{l}\text { Standard } \\
\text { Devialion }\end{array}$ \\
\hline 1 & $9,5()$ & 2.0 & 1.0112 & 0.710 & $(0.522$ & $0.40,0$ & 0.677 & -0.460 & $(0.242$ \\
\hline 1 & 8.50 & 2.0 & $0.0,51$ & 0.57 .1 & 0.598 & 0.562 & $(0.5) 6$ & $-(0,610$ & $(0.0 .39$ \\
\hline 1 & $\varphi(0)$ & 0.5 & 0.9 .39 & 0.977 & 0.974 & 0.924 & 0.95 .4 & $-0.2^{1} ?$ & 0.026 \\
\hline$i$ & 925 & 5.0 & $0.8(0)$ & 0.8 .12 & $0.06,8$ & $(0.539$ & 0.730 & $-0.29_{1}$ & 0.15 .5 \\
\hline 1 & 92.5 & 1.0 & 0.91 .4 & 0.873 & 0.780 & 0.619 & 0.800 & -0.24 .5 & $0.1,31$ \\
\hline$i$ & 87.5 & 1.0 & $0.76,8$ & 0.811 & 0.786 & 0.7 .48 & 0.778 & -0.021 & 0.027 \\
\hline$i$ & 875 & 5.0 & $(0.700)$ & 0.717 & $0.0,32$ & 0.602 & $0.06,5$ & -0.102 & 0.050 \\
\hline$i$ & 90 & 2.0 & 0.818 & 0.8416 & 0.832 & 0.739 & 0.800 & $-0.0)(3,3$ & 0.048 \\
\hline 2 & 90 & 5.0 & 0.0 .40 & 0.750 & $0.6,30$ & $(0.4)(0)$ & 0.70 .3 & -0.147 & 0.191 \\
\hline 2 & 875 & 3.2 & 0.850 & 0.84 .3 & $0.760)$ & 0.6881 & 0.780 & -0.058 & 0.070 \\
\hline 2 & () 25 & 3.2 & 1.080 & 0.8010 & 0.590 & 0.523 & $0.74\}$ & -0.188 & 0.251 \\
\hline 2 & 900 & 2.0 & 1.150 & 0.880 & 0.860 & 0.730 & 0.90 & -0.128 & 0.176 \\
\hline 3 & 900 & 5.0 & 0.877 & 0.895 & 0.820 & 0.706 & 0.82 & $-(0.057$ & 0.084 \\
\hline 3 & 875 & 3.2 & 0.910 & 0.810 & 0.770 & 0.7 .54 & 0.811 & -0.051 & 0.070 \\
\hline 3 & 025 & 3.2 & $1.1,30$ & $(1.910$ & $\cdots$ & 0.370 & 0.803 & -0.256 & 0.391 \\
\hline 3 & $9(1)$ & 2.0 & 0.776 & 0.840 & 0.000 & 0.790 & 0.830 & 0.012 & 0.055 \\
\hline
\end{tabular}
decreases rapidly (strain rate sensitivity

TABLE 3. Summary of Test Dala

- Strain at 40\% strain rate jump. 
RFP-4253

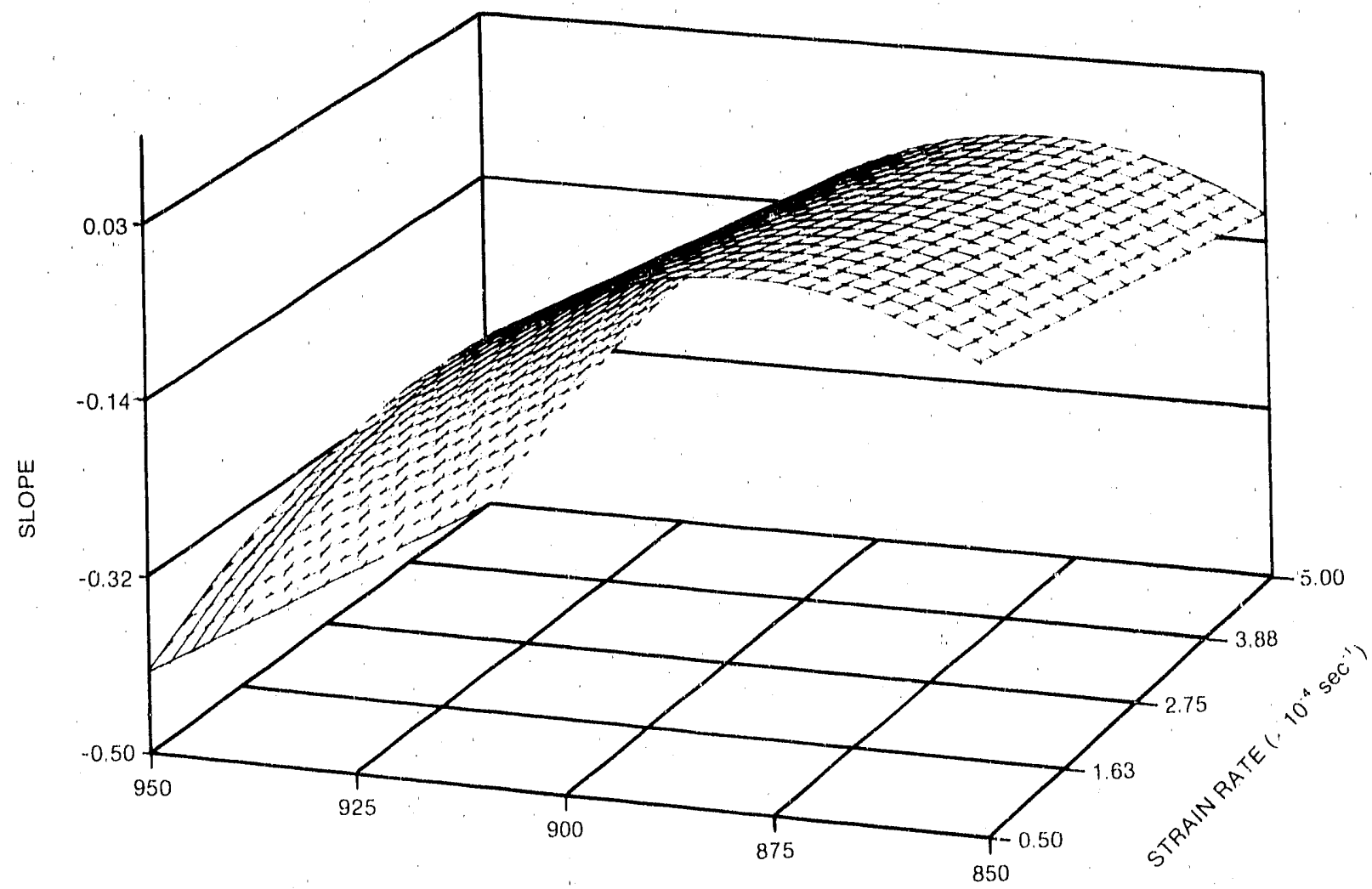

FIGURE 14. Slope as a Function of Strain Ralte and Temperature (Equation 5). The slope variable represents the incremental increase or decrease in strain rate sensitivity per $40 \%$ increment in true strain.

decreases with strain), presumably from grain growth effects caused by imbalance of volume fractions of alpha and beta at the test temperature. At lower temperatures, the slope decreases only slightly across the strain range. This decrease may be because only a small number of samples were tested at $850{ }^{\circ} \mathrm{C}$. With the temperature constant, the slope increases (becomes more negative) with an increasing strain rate at higher temperatures because of the microstructure's ability to accommodate dislocations at the higher strains, thereby limiting grain boundary sliding. Then, as the temperature decreases, the slope becomes constant as a function of strain rate (Figure 14) because the deformation mechanism switches to a dislocation creep mechanism.

In summary, the strain rate sensitivity is a quadratic function of temperature with the maximum occurring at $900{ }^{\circ} \mathrm{C}$. Over the strain rate range tested, strain rate sensitivity increases slightly with decreasing strain rate. However, at temperatures greater than $900{ }^{\circ} \mathrm{C}$, grain growth may act to reduce strain rate sensitivity as strain rate decreases. Incorporating the level of strain into the model shows no temperature effect on the rate at which strain rate sensitivity decreases with increasing strain rate. The slope function (effect of strain) was also a strong 
quadratic function of temperature with a minimum (less negative) near $870{ }^{\circ} \mathrm{C}$. The slope function increases (becomes more negative) dramatically as temperature increases, apparently from grain growth effects. The temperature effect on the slope function is much greater than the strain rate because of the strong effects of grain growth above $900{ }^{\circ} \mathrm{C}$.

\section{Heat Variability Effects on Superplastic Behavior}

The effects of microstructural differences in the heats on superplastic behavior can be examined by analyzing trends in the unaccountable error (actual-predicted) as a function of the heat number. Figures 15 and 16 show residual plots for the mean and slope strain rate sensitivity parameters, respectively, as a function of heat number. Both figures show scatter about a residual value of zero, indicating random errors and no effects on the variables caused by heat number. If one heat consistently indicated a positive or negative residual, a variable related to the heat, such as microstructural variations, could affect the superplastic behavior.

Differences in chemical compositions of the heats (Table 1) were not enough to cause major differences in the microstructures. Although Heats 1 and 3 show some unrecrystallized grains in Figure 5, the microstructural differences at the test temperature remained small due to recrystallization and phase changes. The most important microstructural characteristic is probably the grain uniformity. Although the grain aspect ratios were

FIgURE 15. Unaccounted Error (Actual - Predicted) as a Function of Heal Number for Prediction of the Mean $m$ Value. The variables used in the prediction of the mean $m$ value are shown in Equation 3.

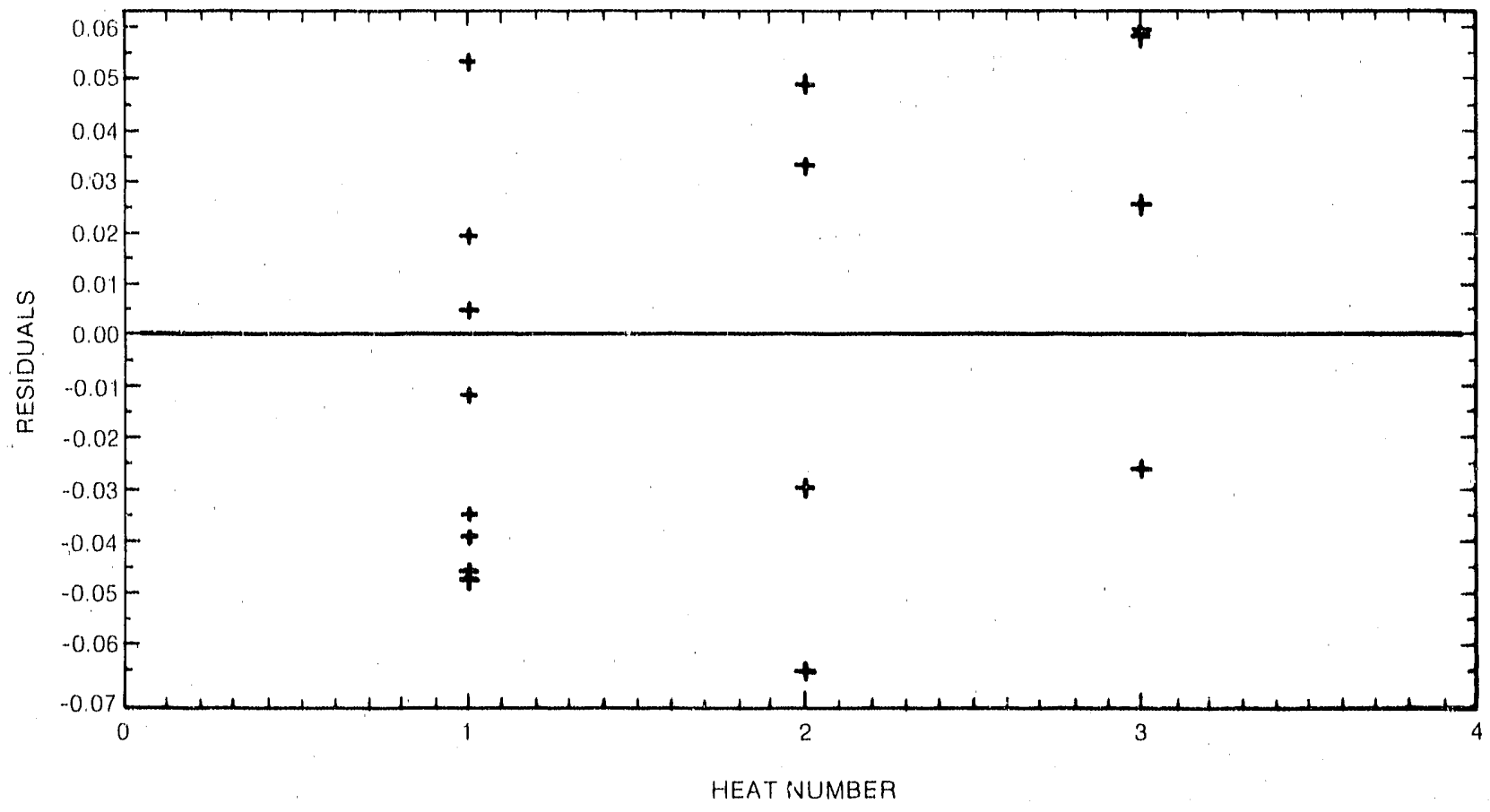


RFP-4253

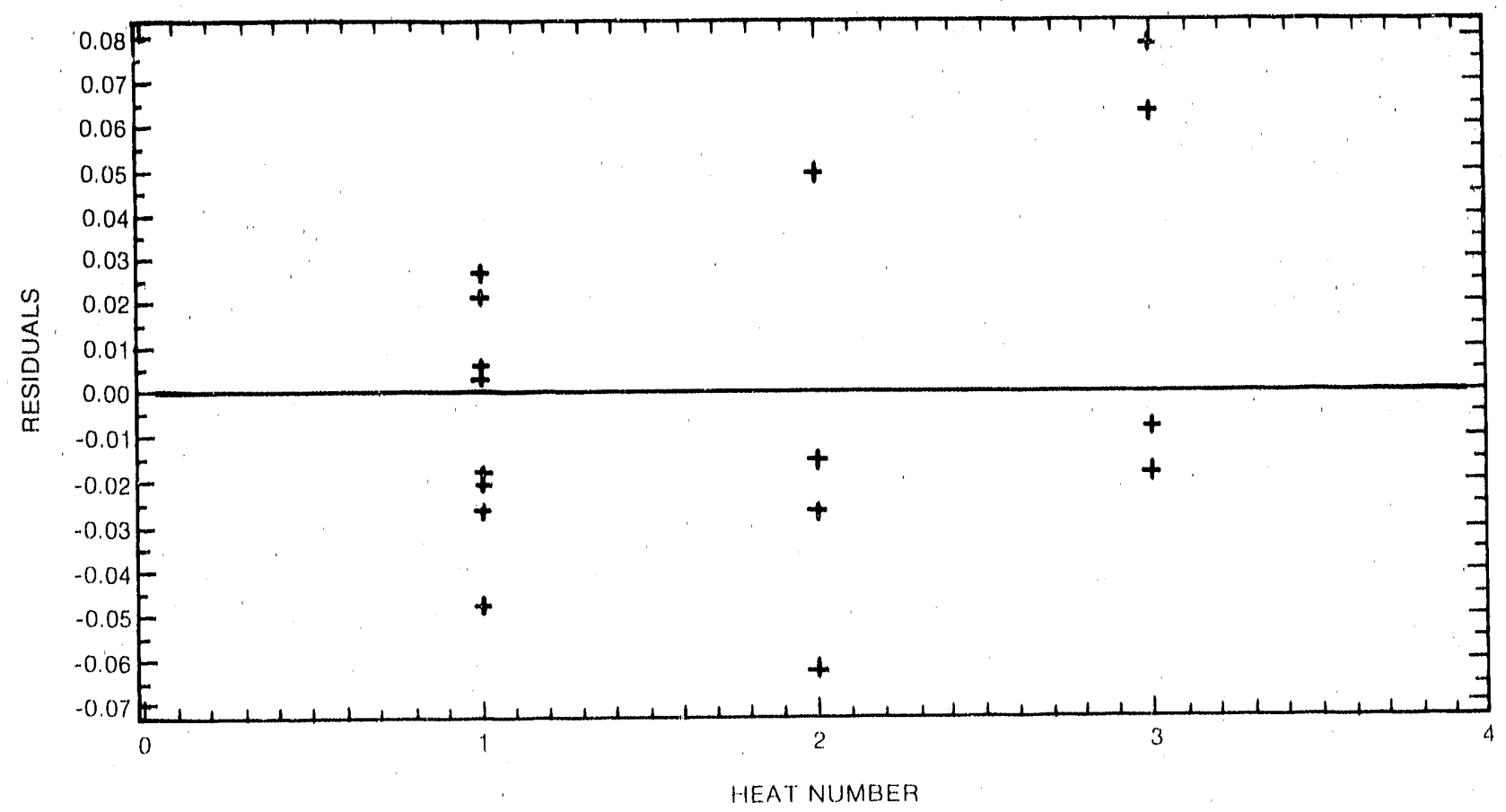

FIGURE 16. Unaccounted Error (Actual - Predicted) as a Function of Heat Number for Prediction of the Slope Valuc. The variables used in the prediction of the slope value are shown in Equation 5.

different, the grains were uniform; i.e., the same aspect ratio across the entire specimen. Grain aspect ratios greater than 1.0 limit the grains' ability to rotate during deformation, leading to the possible rupture of the sample with little necking. ${ }^{12}$ However, since none of these samples were taken to failure, the differences in grain aspect ratio were indistinguishable.

\section{MODEL FOR SUPERPLASTIC FORMING OF Ti-6Al-4V}

\section{Mechanism and Model for Superplastic Deformation}

Several mechanisms for the occurrence of superplastic behavior have been proposed, all of which include grain boundary sliding as a dominant mechanism. However, in the context of diffusional controlled deformation mechanisms, the dominant mechanism cannot be rate controlling at the same time. Grain boundary sliding cannot occur continuously without sonie accommodation at the interface or within grains. Additionally, as the grains move in a three-dimensional array, they move out of their original planes and fill voids in other planes. For grain rearrangement to occur, thr grains suffer some shape change; but because of differences in sliding rates, grain rotation occurs. In polycrystalline materials, two grains cannot slide past each other without impinging on a third grain. Therefore, the differences in the models presented to date are the methods of accommodation for grain boundary sliding and grain rotation during deformation, which fall into two groups: diffusional accommodation and 
accommodation caused by dislocation motion. The dislocation motion accommodation mechanisms can be further grouped into accommodation processes caused by dislocation pileups in the grains or interfaces attributed to motion of individual dislocations. ${ }^{14}$

The model that suggests accommodation by diffusional mechanisms by Ashby and Verral (AV) ${ }^{15}$ was used extensively in several irıvestigations. ${ }^{2,11,16}$ Although this model qualitatively demonstrated correlations on strain rate sensitivity effects, it often does not agree with the mechanical details of superplastic behavior. Hamilton et al. ${ }^{11}$ and Wert ${ }^{2}$ show excellent agreement with the AV model and experimental data; however, Hamilton ${ }^{11}$ reported development of a texture during deformation, which cannot be explained with a diffusional accommodation mechanism.

In the case of the dislocation motion accommodation models, the two groups produce the same functional dependence between stress and strain rate with the exception of a constant. These models predict the deformation behavior well at low strain rates. However, the dislocation motion accommodation models predict a value of 0.5 for $m$ and do not display a sigmoidal relationship between stress and strain rate at higher strain rates. Despite these drawbacks, proponents describe superplastic behavior as an extension of creep mechanisms in which grain boundary sliding is controlled by a dislocation motion mechanism. Although the models presented do not totally describe the major evidence of superplasticity, both models predict similar effects of temperature (single-phase alloys), grain size, and diffusivity on the stress strain rate relationship despite the different mechanisms in which grain boundary sliding is controlled.

Examining the data for $\mathrm{Ti}-6 \mathrm{Al}-4 \mathrm{~V}$ and the work of Hamilton et al: ${ }^{16}$ and Wert ${ }^{2}$ including Ti-6Al-4V, the AV model appears to work very well for this alloy system. The constitutive relation derived using this model is:

$$
\begin{aligned}
& \dot{\epsilon}=\underbrace{\frac{100 \Omega D^{2} v}{k \mathrm{Td}^{2}}\left[0 \cdot \frac{0.72 \gamma}{\mathrm{d}}\right]\left[1+\frac{3.3 w D_{b}}{d D_{v}}\right]}_{\begin{array}{c}
\text { Grain boundary sliding and } \\
\text { diffusional creep }
\end{array}}
\end{aligned}
$$

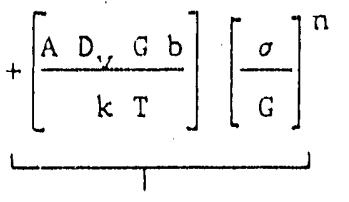

$$
\begin{aligned}
& \text { Dislocation } \\
& \text { creep }
\end{aligned}
$$

where:

$\epsilon$ - Strain rate

$\Omega$ - A.tomic volume

d - Grain size

$D_{v}-$ Bulk diffusivity

$\gamma$ - Grain boundary energy

n,A - Constants

T - Temperature

o - Applied stress

b - Burger's vector

w - Grain boundary width

$\mathrm{D}_{\mathrm{b}}$ - Grain boundary diffusivity

$\mathrm{G}$ - Shear modulus

K - Boltzman constant

As indicated in Equation 6, the two terms represent contributions to deformation 


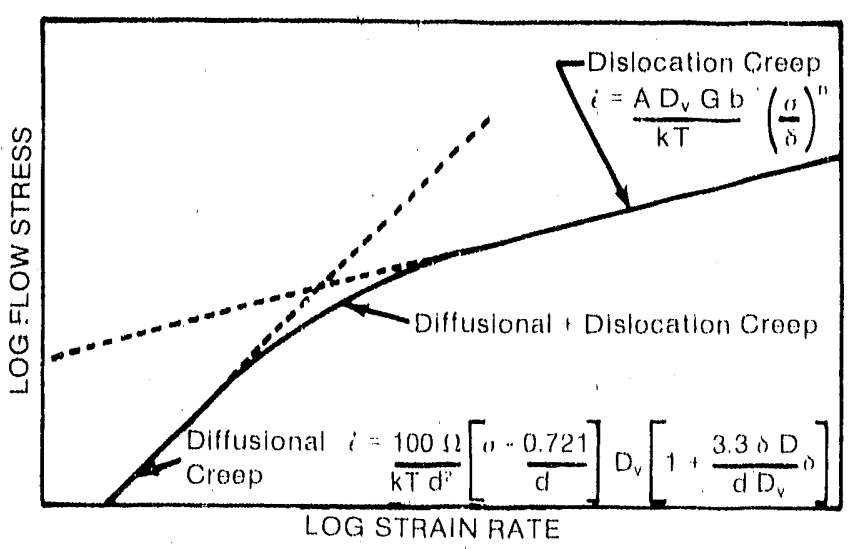

FIGURE 17. Example of the Diflerent Regions of $\sigma / \dot{\epsilon}$ Behavior as Described by the Ashby-Verrall Model (Reference 15).

from grain boundary sliding plus diffusional creep and from dislocation creep. Figure 17 shows the $\log (\sigma)$ dependence on $\log$ $(\dot{\epsilon})$ for each term of Equation 6 and for the sum of these two contributions to deformation. The strain rate range where dislocation creep is the dominant deformation mechanism is customarily termed Region III. Similarly, Region "I is the strain rate range where grain boundary sliding plus deformation accommodation mechanism dominates. ${ }^{2}$

The AV model predicts a value of $m$ near 1 for deformation in Region II. Experimental results show that values of $m$ are near 0.5 for some alloys, while values above 0.7 can be found for other alloys. ${ }^{2}$ It is evident that the understanding of the fundamental deformation mechanism contributing to superplasticity is insufficient to allow prediction of the strain rate sensitivity for superplastic deformation. Although the actual prediction of $m$ cannot be made, the use of existing models can be used to predict the effects of processing parameters, strain rate, and temperature on the strain rate sensitivity relative to material parameters.

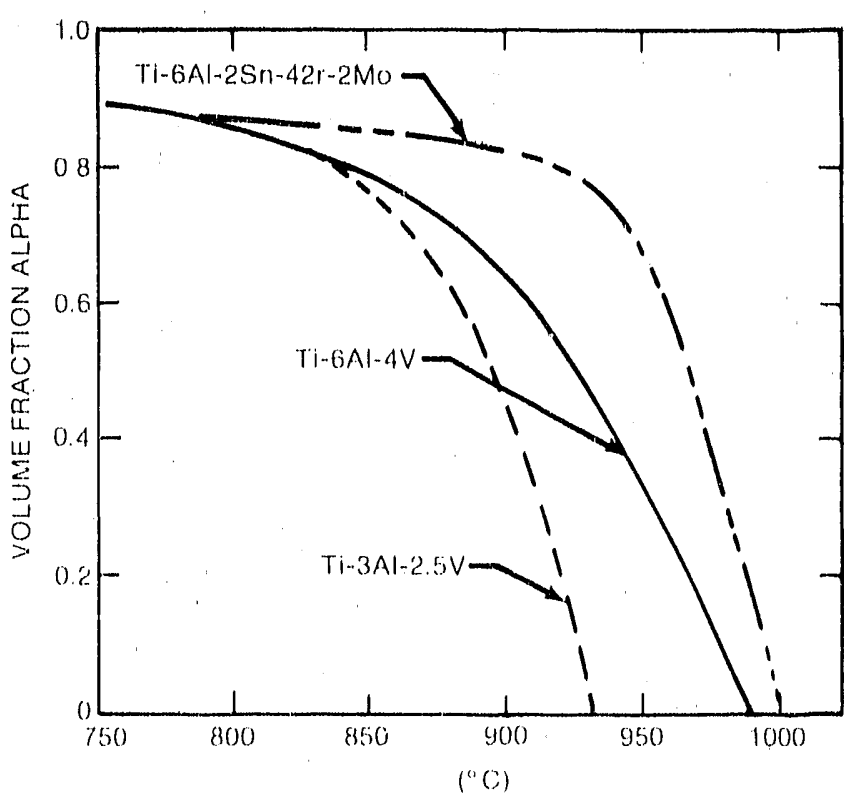

PIGURE 18. Vartiation of Alpha Volume Fraclion Wilh Tenperalure for Three Titanium Alloys (Reference 11).

\section{Effects of Temperature}

Equation 6 can be used to determine the deformation in single-phase and guasisingle-phase alloys. However, to predict the superplastic behavior of duplex alloys, additional assumptions are necessary to account for individual deformation behavior of the phases present. At the temperatures of interest, the phase diagram for Ti-6Al-4V dictates the presence of two phases: alpha and beta. As the temperature increases, the volume of the higher temperature beta phase increases at the expense of the alpha phase, as shown in Figure 18.

In Ti-6Al-4V, diffusivity of the beta phase is approximately two orders of magnitude greater than the alpha phase because of its more open structure. ${ }^{11}$ Therefore, as the beta phase increases, the diffusioncontrolled accommodation rate-controlling 
mechanism becomes less of a barrier to grain boundary sliding, thereby allowing superplastic deformation at higher strain rates. In addition to increasing the beta phase volume fraction, the higher temperatures also increase thermal vibrations in the latice, thereby increasing the probability that atoms will overcome the activation barrier for diffusion, hence increasing diffusivity of the individual phases.

In the case of Ti-6Al-4V, Hamilton et al. ${ }^{16}$ successfully modeled superplastic behavior with the AV model, assuming isostrain rate deformation and the rule of mixtures to calculate stress as a function of strain rate with varying amounts of alpha and beta in the microstructure. In the absence of grain growth, the net effect on increasing amounts of beta was to increase the strain rate at which superplastic behavior occurs (i.e., high $\mathrm{m}$ at higher strain rates) by shifting the $\log \sigma-\log \dot{E}$ curve to higher strain rates shown in Figure 19. Because $m$ increases the elongation as fracture increases, a volume fraction increase of beta provides improved superplasticity at the strain rate in question.

\section{Effect of Grain Size}

An important requirement for superplastic behavior is a fine grain size. Superplastic behavior requires temperatures on the order of half the melting point; thus, a fine grain size may be maintained only with the presence of a second phase. In Ti-6Al-4V, the two-phase mixture of alpha and beta with different crystal structures provides the necessary conditions.

However, as shown in Figure 18, at the higher temperatures, a significant portion of the microstructure consists of beta,
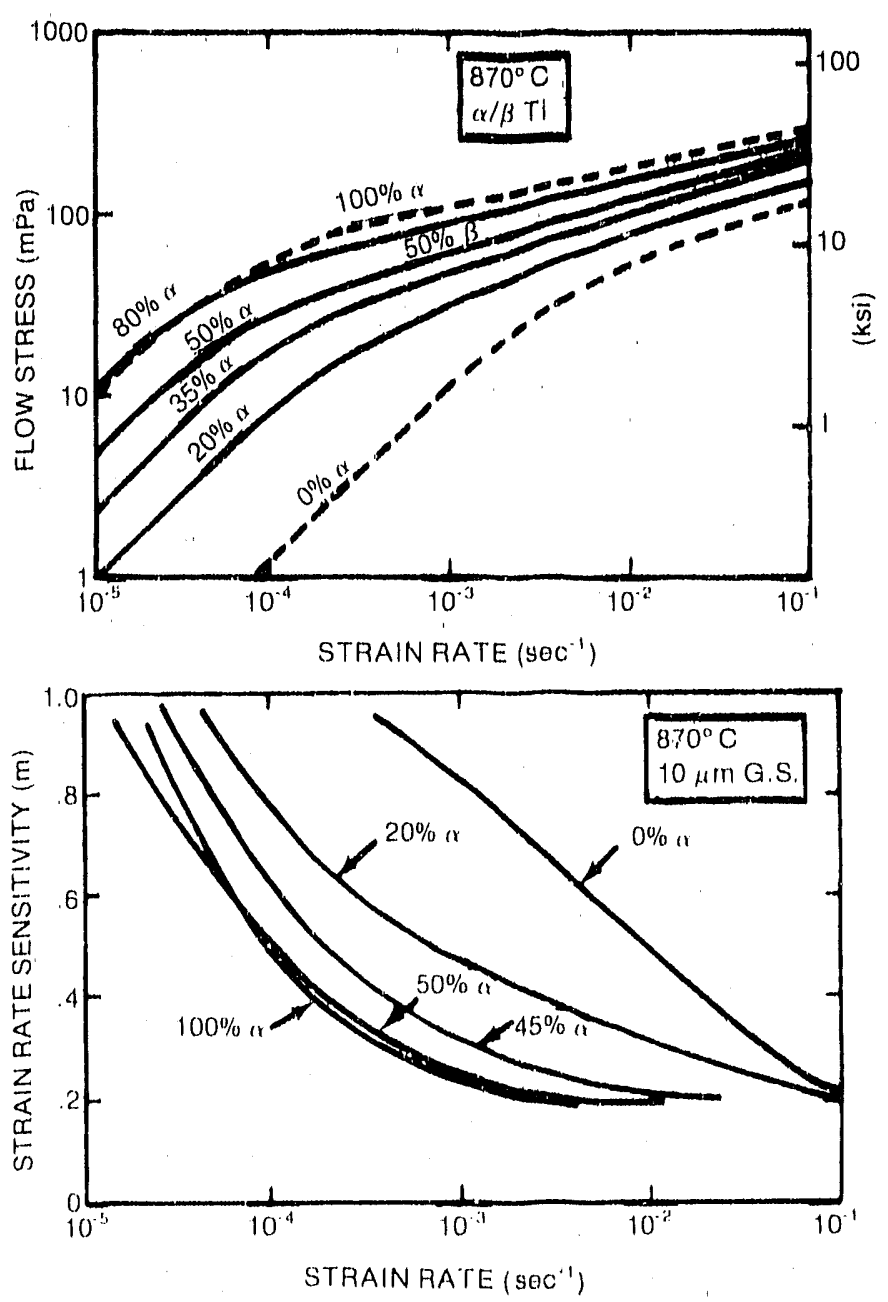

FIGURE 19. Influnce of Phase proportions on $\sigma / \dot{\epsilon}$ Propertics (top) and Strain Rate Sensitivity, m, (Bottom) for a Fixed Average (irain Size of 10 $\mu \mathrm{m}$ Based on Adjusting the Asbhy-Vurrall Model and IsoStrain Rate Assumptions for the Phase Behavior (Reference 16).

resulting in grain growth. The AV model shows strain rate is inversely proportional to grain size. Therefore, grain growth lowers the strain rate at which superplastic behavior occurs, thus shifting the curve in Figure 17 to the left. As a result, increased grain size switches the deformation 
mechanism from a mixed mechanism of grain boundary sliding and dislocation creep to purely dislocation creep mechanisms, which decrease strain rate sensitivity significantly.

The effect of grain growth reducing the value of $m$ at the higher temperatures is seen in Figures 10, 11, and 13. In each figure, the increase in $\mathrm{m}$ with increasing temperature is reversed at the higher temperatures where a lack of alpha phase in the microstructure permits rapid grain growth. At the lower temperatures where a significant portion of the structure is alpha, the grain growth is slow because of a small thermal activation.

Effects of temperature and grain growth on strain rate sensitivity are best illustrated in Figure 13. Several investigators have shown that optimum superplasticity (highest value of $m$ ) occurs at intermediate temperatures where approximately equal volume fractions of alpha and beta limit grain growth. ${ }^{8,11}$ Figure 18 shows that this condition exists between 900 and $940{ }^{\circ} \mathrm{C}$. The data in Figure 13 suggest that the optimum temperature range is shifted to lower temperatures at the higher strains, suggesting that strain probably contributes to the decrease in $m$ as well as grain growth. Work by Hamilton and Ghosh ${ }^{3}$ shows that grain growth is accentuated by the strain rate; thus, strain-rate-induced grain growth may account for lowering the optimum temperature. The effect of phase proportions on the strain rate sensitivity calculated with the AV model in Figure 19 does not incorporate concurrent grain growth. Adding grain growth effects would shift the 0 and $20 \%$ alpha curves to the left of the $50 \%$ alpha curve, maximizing $\mathrm{m}$ for a constant strain rate when the volume fractions of alpha and beta are approximately ecqual. ${ }^{11}$

\section{Effects of Strain and Strain Rate}

At a constant strain rate, the time for grain growth to occur increases as the strain increases, thus decreasing strain rate sensitivity (Figure 13). The rate of growlh increases as the teruperature increases, signified by the drop in $\mathrm{m}$, as indicated by the slope parameter in Figure 14. The magnitude of the drop in m also increases as the strain rate increases in Figure 14 perhaps from strain-rate-induced grain growth, further amplifying grain growth kinetics. But, Ghosh and Hamilton ${ }^{9}$ show that lowering the strain rate by an order of magnitude results in a coarser grain size after a strain of 1.6. Therefore, at slower strain rates, the added time for grain growth outweighs the reduced kinetics. In the range of interest, strain rate sensitivity is a strong function of strain rate from changes that occur in the deformation mechanisms. Therefore, the effects of grain growth as functions of strain rate (decrease in $\mathrm{m}$ with decreasing strain rate) are not observed in Figure 14.

The data suggest that in the strain range tested, the deformation mechanism is in the transition from grain boundary sliding to dislocation creep. At low strain rates, where the AV model suggests a constant $\mathrm{m}$, the strain and temperature become important factors because of grain growth effects on strain rate sensitivity. Strain rate increases in this region (II) magnify the effects of strain and temperature on deformation behavior, leading to a decreasing $\mathrm{m}$ with increasing strain rate. 
At strain rates in which the deformation mechanism makes the transition from grain boundary sliding to dislocation creep, the effects of temperature and strain become less important because of the significant decrease in $\mathrm{m}$, which occurs as dislocation creep becomes the dominant mechanism. The magnitude of the change in $\mathrm{m}$ is shown by examining the change in slope of the tangent to the curve in Figure 17 as strain rate increases. Because the strain rate range tested was in the transition region, strain rate sensitivity decreased rapidly as the strain rate increased.

Drop in strain rate sensitivity as a function of strain rate was lower in Figure 10 than in Figure 12. The linear regression in Figure 12 was based on strain rate only, while the model in Figure 10 accounted for temperature variations as well as strain rate. The coefficients of dete minations for the linear regressions in Figure 12 were quite low, indicating wide variations, possibly caused by temperature. Nevertheless, the data at $925^{\circ} \mathrm{C}$ in Figure 7 agree well with data at the same temperaature in Figure 12, although measurements were made at different strains. The mechanisms of superplastic behavior in this strain range support behavior similar to Figures 7 and 12. It is unclear why accounting for temperature behavior in the model lessens strain rate effect on the strain rate sensitivity.

\section{SUPERPLASTIC FORMING OF Ti-6AI-4V}

For superplastic forming to move from the laboratory to an industrial process, laboratory characterization for reflecting material behavior in forming operations becomes important. The parameter commonly used as a measure of superplastic formability is the tensile elongation at optimum temperature and strain rate. The strain rate sensitivity correlates very well to the tensile elongations; therefore, the optimum temperature and strain rate can be found by maximizing the value of m. During superplastic forming, significant variations in strain rate and temperature can occur; thus, a conservative estimate of the optimum parameters would be the minimum, $m$. At any strain rate, the maxinum strain rate sensitivity occurs at temperatures near $900{ }^{\circ} \mathrm{C}$ (using Equation 4).

Strain rate was not as significant as temperature in examining strain effect on the strain rate sensitivity. Equation 5 suggests that grain growth effects are limited at temperatures below $875^{\circ} \mathrm{C}$. At $900{ }^{\circ} \mathrm{C}$, the effects of grain growth could lower the strain rate sensitivity by $25 \%$, lepending on the strain involved. From the data, it is apparen, that temperature is a critical factor and, depending on the strains, should he between 875 and $900{ }^{\circ} \mathrm{C}$ for optimum formability. In considering the strain rate, the value of $m$ increases with decreasing strain rate to approximately $10^{-4} \mathrm{sec}^{-1}$. Therefore, the strain rate should be selected in conjunction with factors such as part geometry and forming time to limit grain growth and cluctility losses during forming.

The characterization of superplastic behavior includes development of constitutive relations for superplastic flow because reasonably accurate control of the pressurization cycle during forming is required. Computer programs that calculate pressure cycles require that material characterization be of the form presented in Equation 2. In selecting the temperature range of 875 to $900{ }^{\circ} \mathrm{C}$, the minimum 
value for $\mathrm{m}$ can be determined easily. Howe ver, the stress constant, $\mathrm{K}$, is not readily available and must be approximated. Comparing Figures 7 and 12, the magnitude of the drop in $m$ as a function of strain rate in the step strain rate test was similar to the data derived from the jump test. The strains in the step strain rate test were small to eliminate grain growth effects.

In considering the strain and subsecquent grain size, Hamilton and Ghosh ${ }^{17}$ shoved good agreement between the step strain rate test and jump test. Ideally, the step strain rate test should be run at the temperature and strain rate in question to determine the stress constant and strain rate sensitivity. In the absence of this clata, the value attained at $925^{\circ} \mathrm{C}$ can be used provided that a strength increment is adkled to account for the changing mix of alpha and beta in the microstructure. Of course, this procedure assumes a linear log $\sigma-\log \dot{\epsilon}$ behavior, which may or may not be a bad assumption provided any changes in the slope, $m$, of the line are incorporated in finding the strength increment.

\section{SUMMARY}

1. The superplastic formability of Ti-6Al$4 \mathrm{~V}$ is strongly influenced by temperature. The flow stress increases with decreasing deformation temperature. Like the uniform elongation, the strain rate sensitivity is maximized at $900{ }^{\circ} \mathrm{C}$ in the temperature range tested.

2. In the strain rate range tested, $m$ increases slightly as strain rate decreases. Over a much broader range, the trend remains the same but increases in magnitude.

3. It is apparent that grain growth results in decreased strain rate sensitivity with increasing strain during superplastic forming. The magnitude of this drop is a strong function of temperature, which minimizes at $875^{\circ} \mathrm{C}$.

4. The temperature range in which strain rate sensitivity is maximized was less than the range in which equal volume fractions of alpha and beta coexist probably caused by strain-rate-induced grain growth during deformation.

5. In the strain rate range tested at optimum temperatures, super-plastic behavior is dominated by a combination of grain boundary sliding and dislocation creep. The accommodation mechanism for the grain boundary sliding was not determined in this study.

6. The microstructural variability within the three heats tested did not result in significant differences in superplastic behavior.

\section{REFERENCES}

1. O. D. Sherby and J. Wadsworth, Deformation, Processing and Structure, $\mathrm{p}$ 355. American Society for Metals, 1985.

2. J. A. Wert, Mechanical Properties and Phase Transformations in Engineering Materials, p 307, The Metallurgical Society of AIME, 1986.

3. C. H. Hamilton and A. K. Ghosh, Titanium '80: Science and Technology, 
p 1001, The Metallurgical Society of AIME, 1980.

4. C. H. Hamilton and G. W. Stacher, Metals Progress, Vol 109, p 34, March 1976.

5. M. M. McDonald, Superplasticity of Metals With Reference to Ti-6Al-4V, RFP-3909, Rockwell International, Rocky Flats Plant, Golden, CO, August 11, 1986.

6. C. H. Hamilton and A. K. Ghosh, Met. Trans. A, Vol 11A, p 1494, August 1980.

7. S. M. Sastry et al., "Experimental Verification of Process Models," American Society for Metals Conference Proceedings, Sept. 21-23, 1981, American Society for Metals, 1983.

8. G. E. Dieter, Mechanical Metallurgy, 2nd ed., p 350, McCraw Hill, 1976.

9. A. K. Ghosh and C. H. Hamilton, Met. Trans. A, Vol 10A, p 699, June

10. R. Raj and A. K. Ghosh, Acta Met., Vol 29, p 283, 1981.
11. C. H. Hamilton, "Superplastic Forming," American Society for MetalsSymposium, March 22, 1984, Los Angeles, Calif., p 13, American Society for Metals, 1985.

12. N. E. Paton and C. H. Hamilton, Met. Trans. A, Vol 10A, p 241, February 1979.

13. J. A. Wert and N. E. Paton, Met. Trans. A, Vol 14A, p 2535, December 1983.

14. A. Arieli and A. K. Mukherjee, Met. Trans. A, Vol 13A, p 717, May 1982.

15. M. E. Ashby and R. A. Verrall, Acta. Met., Vol 21, p 149, 1973.

16. C. H. Hamilton, A. K. Chosh, and M. W. Mahoney, Advanced Processing Methods for Titanium Alloys, p 129, The Metallurgical Society of AIME, 1982.

17. C. H. Hamilton and A. K. Ghosh, Met. Trans. A, Vol 11a, p 1494, August 1980. 

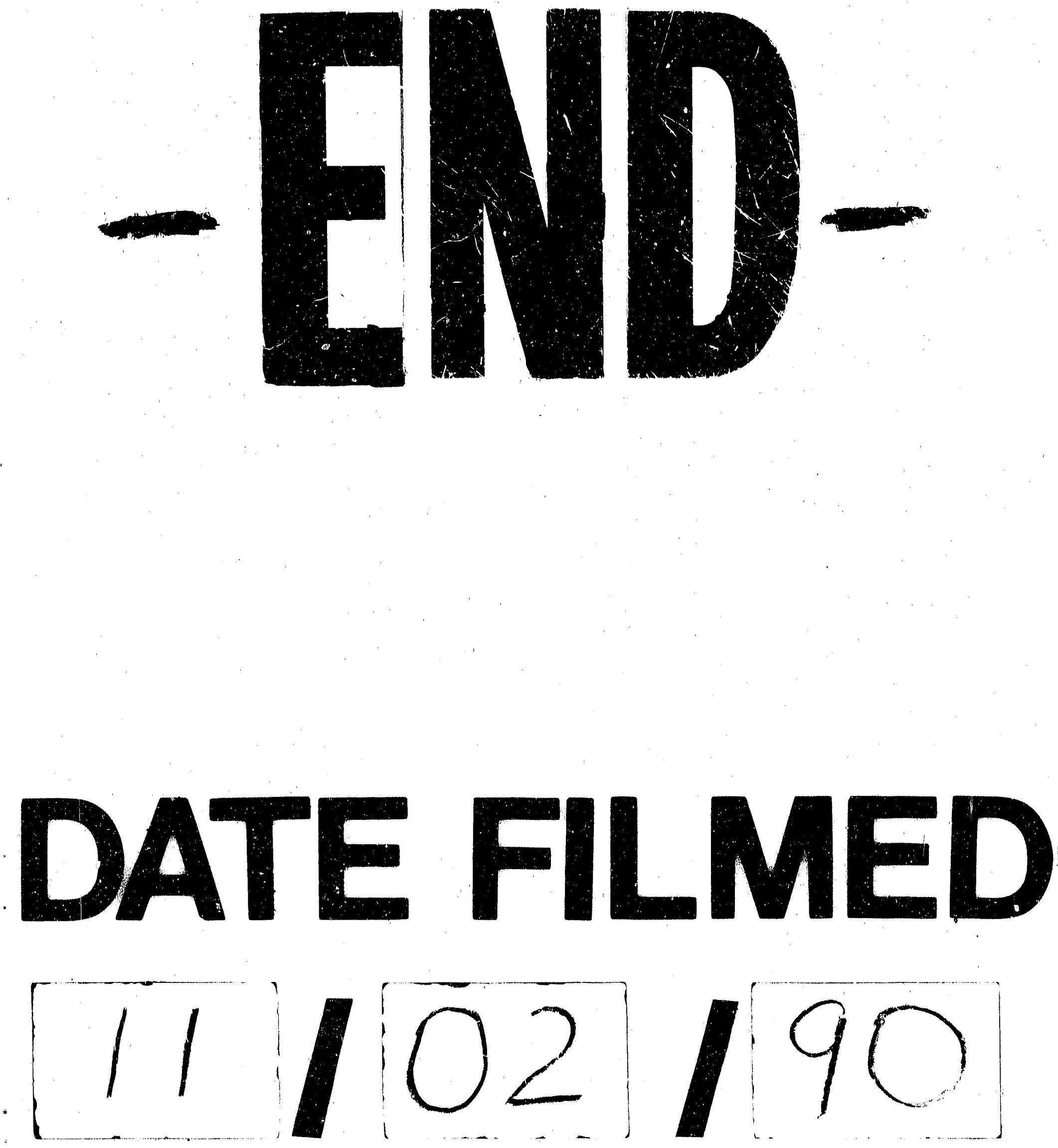

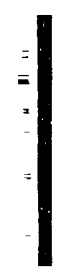


